\title{
El lenguaje ritual del fuego en los mayas del periodo Clásico: un acercamiento
}

\section{The Ritual Language of Fire among the Maya of the Classic Period: an Approach}

\author{
Martha Ilia NÁJera Coronado \\ Centro de Estudios Mayas, Instituto de Investigaciones Filológicas, \\ Universidad Nacional Autónoma de México, México
}

\begin{abstract}
Resumen: El valor simbólico del fuego es polisémico, aunque principalmente es un marcador temporal y por tanto se enciende en momentos liminares, como puede ser el ascenso de un gobernante, la inauguración de un espacio o de un objeto para convertirlos en sagrados, en momentos de comunicación con los antiguos gobernantes, en la fundación de una ciudad. De hecho, lo que se buscaba era la recreación de un mito cosmogónico para regenerar el mundo.

Este artículo tiene como objetivo mostrar, desde la historia comparada de las religiones, algunos de los principales rituales de fuego desarrollados durante el periodo Clásico en diferentes sitios del área maya. Asimismo, pretende, mediante un análisis comparativo, encontrar modelos que nos permitan acercarnos a su sentido, teniendo en cuenta similitudes y diferencias. Estos rituales se llevaban a cabo por la nobleza y se han conservado en distintas imágenes e inscripciones en numerosos sitios del área maya. Si bien existen muchas investigaciones que mencionan los rituales de fuego, los datos se encuentran dispersos y pueden perder su verdadero sentido. Por ello, en este primer acercamiento, se busca conjuntar e integrar algunos datos sobre la pirolatría practicada por los mayas; de aquí que sólo se aproximará a temas específicos como los mitos del fuego, las ceremonias para taladrarlo o encenderlo, rituales de fuego en las cuevas, la introducción del fuego en diferentes espacios, edificios, tumbas y sus posibles valencias simbólicas.
\end{abstract}

Palabras clave: culto al fuego, mitos del fuego, rituales de poder, ceremonias de encendido del fuego, comunicación con los antepasados.

AвSTRACT: The symbolic value of fire is polysemic, although it is mainly a temporary marker and, therefore, lights up at liminal moments, such as the rise of a ruler, in the inauguration of a place or an object in order to make them become sacred; in moments of communication with ancient rulers, and in the foundation of a city. In fact, what was sought was the recreation of cosmogonic myth in order to regenerate the world.

This article aims to show, based on the comparative history of religions, some of the main fire rituals developed in different sites of the Maya area, during the Classic period. Also, through a comparative analysis, it pretends to find models that allow 
us to understand its meaning, taking similarities and differences into account. These rituals were carried out by the nobility and have been preserved in different images and inscriptions in numerous sites of the Maya area. Although fire rituals are mentioned in many research papers, the data is scattered and its true meaning could be lost. Thus, in this first publication, the aim is to combine and integrate some data on pyrolatry practiced by the Maya; therefore, it will only deal with specific topics such as the myths of the recreation of fire, the ceremonies to light it, the rituals of fire in caves, the introduction of fire in different spaces, buildings, tombs, and their possible symbolic significance.

KEYwORDS: Fire cult, fire myths, power rituals, ceremonies to light fire, communication with ancestors

RECEPCIÓN: 12 de febrero de 2019.

ACEPTACIÓN: $1^{\circ}$ de marzo de 2019.

DOI: 10.19130/iifl.ecm.2019.54.993

\section{Introducción}

La ritualidad maya ha despertado un gran interés entre los estudiosos de esta antigua cultura. La relevancia de su vida religiosa influía en sus múltiples actividades cotidianas, de ahí que su conocimiento permita obtener una mayor comprensión de su realidad y desarrollo cultural. Por supuesto, llevaban a cabo un sinfín de rituales, y entre ellos he elegido para este artículo solo algunos en los que el fuego era el centro del culto. Los textos que abordan esta temática son diversos; salvo algunas relevantes excepciones, la mayor parte de las referencias se localizan dispersas en obras de distinta índole y se citan tangencialmente, es por ello que mi interés es reunirlas dentro de su contexto sagrado y tratar de encontrar su estructura interna.

Entre los rituales están aquellos que se celebraban en las comunidades, al interior de los hogares o en los campos de cultivo, de los cuales tenemos escasos datos precisamente porque era un culto privado que no dejaba vestigios; no obstante, en los pueblos contemporáneos, persisten algunos indicios de esa religiosidad, gracias a que permanecieron reservados al interior de los hogares. En contraste, de los rituales de carácter público durante el periodo prehispánico han quedado muchos vestigios porque generalmente eran llevados a cabo por la nobleza y subsistieron testimonios en diferentes contextos, tal vez muchos de ellos no se desarrollaban ante una multitud, pero sí tenían como testigos aquellos

que evidenciaban la autoridad de los más poderosos. Éstos eran efectuados por los gobernantes, la nobleza, los especialistas en lo sagrado, y su finalidad consistía en reafirmar su autoridad y legitimidad. Se podría decir, desde la categorización de Bell (2009: 91-135), que eran rituales políticos, que se llevaban a cabo para mostrar y promover el poder de las instituciones políticas; algunos formaban parte del culto al gobernante, y era este culto el que creaba su poder, pues se percibía como algo natural y correcto. 
Para ello era necesario elaborar argumentos sobre la naturaleza del poder y que éste se hiciera tangible y eficaz; se utilizaban diferentes elementos, objetos y actos simbólicos, lo que posicionaba a un grupo de personas como una comunidad coherente y ordenada sobre la base de valores y objetivos. Por supuesto, entre los rituales que llevaba a cabo esa nobleza, estaban aquellos en los que el fuego, por sus múltiples significados, jugaba un papel central.

\section{El simbolismo del fuego}

El fuego es un concepto plástico, dinámico, del pasado y del presente; es uno de los símbolos polisémicos que se manifiesta en toda su ambigüedad como elemento de cohesión social, de poder, de fertilización, además de ser un elemento indispensable para la siembra del maíz; no obstante, es un fenómeno poliédrico porque es a su vez destructor, no sólo daña al enemigo y destruye pueblos y cosechas, sino también provoca enfermedades como llagas, granos, quemaduras. Los grupos mayas tuvieron una construcción religiosa en torno al fuego, porque surgió de la experiencia en su vida, a partir de la observación de sus propiedades en el mundo natural y material; a su vez, le atribuyeron ciertas facultades que fueron más allá de la vida diaria y lo situaron en un lugar relevante de su sistema religioso (Limón, 2001: 14).

El culto al fuego como elemento sagrado fue común durante el periodo Clásico en ceremonias organizadas por los grupos en el poder, lo que responde a que su uso sagrado es jerárquico; es por ello que aludiré a sus múltiples valencias como potencia sagrada, de purificación, protección, agregación, fundación, transformación y cómo se asimiló a las características o funciones de algunos dioses. Asimismo, es un centro común de la existencia social, garantía de la supervivencia de la comunidad.

Este texto es un primer acercamiento, para desarrollar con posterioridad una visión más completa del ceremonial del fuego y sus significados durante la época prehispánica y colonial temprana; los datos que proporciono, hasta este momento, provienen de diversos estudios de epigrafistas sobre el periodo Clásico: Bernal (2006, 2011, 2014a, 2016), Brady (2005), Colas (2000), García Juárez (2016), Grube (2000), Houston et al. (2003), Lacadena (2003, 2004), Sheseña (2005, 2014, 2015), Stuart (1998, 2010), Taube $(1998,2004)$, entre muchos otros, de quienes ofreceré solo algunos ejemplos relevantes a fin de ilustrar contadas ceremonias del fuego, y me restrinjo a los datos de monumentos escultóricos de diversos sitios del área maya (ver Mapa 1). Entre los temas que abordaré, al ser un primer acercamiento, he elegido para este trabajo los mitos referentes a su creación, las diferentes formas de encender el fuego, lo que se ha llamado "entrada de fuego" a diferentes construcciones, incluyendo las tumbas, y algunos de los rituales llevados a cabo en cuevas. ${ }^{1}$

\footnotetext{
${ }^{1}$ Por ello, no abarco en esta primera publicación lo que significó el culto al fuego en todos sus aspectos; omito por el momento algunos tan relevantes como el llamado puk k'ahk' o pukil k'ahk',
} 


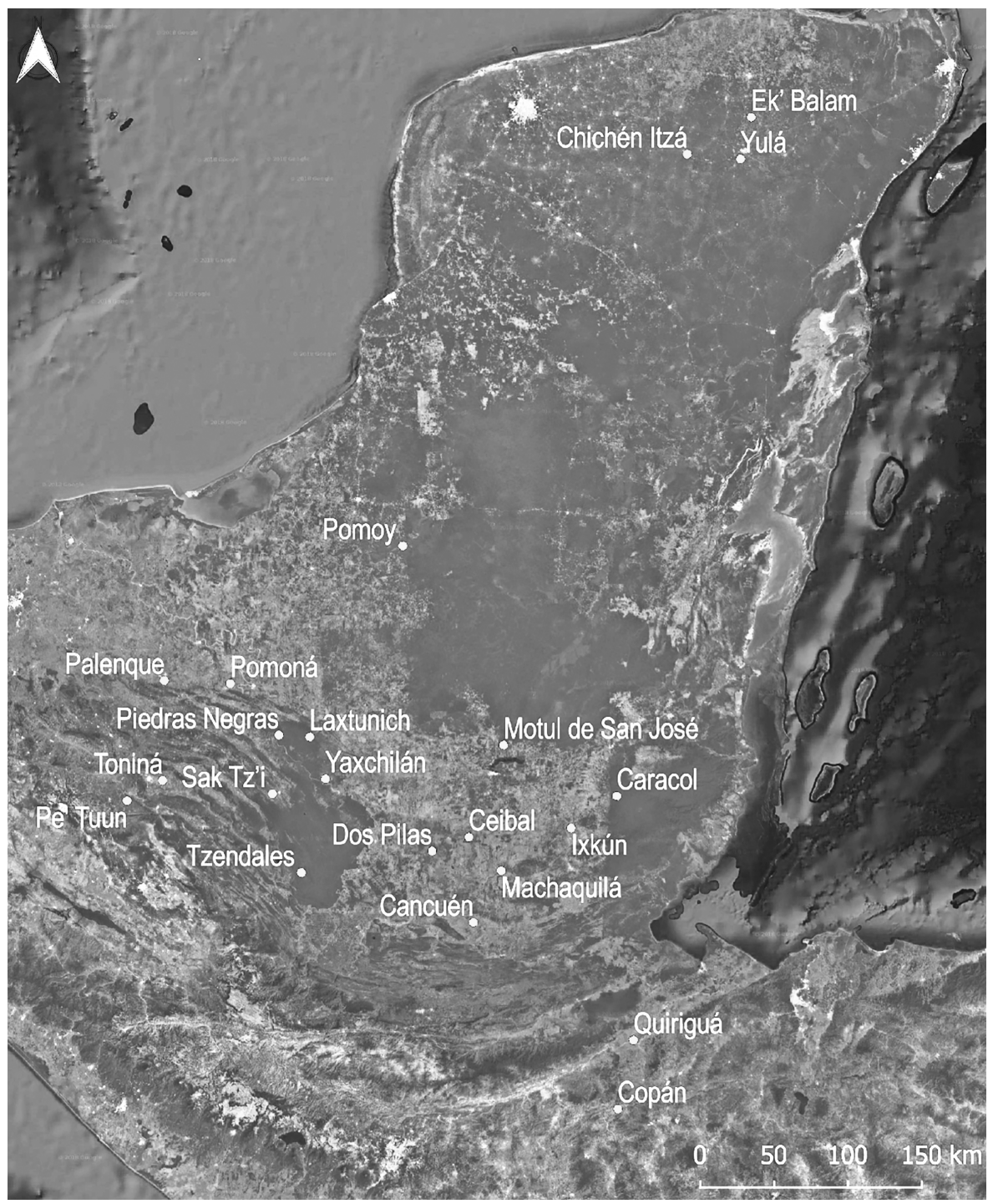

Mapa 1. El área maya con los sitios arqueológicos citados. Tomado de Google Maps con QGIS y "QuickMapServices" modificado por Chrystian Reyes Castillo.

“arrojar fuego", que en realidad, de acuerdo con Sheseña (2014: 67; 2015: 141-142) podría tratarse de "colocar brasas"; de manera tangencial cito la acción de sahumar que utilizó el logograma p’ulil k'ahk' ni la diferencia de significados entre una exhumación o bien una incineración al fallecimiento de un individuo (Tiesler y Scherer, 2018); los sacrificios humanos vinculados con el fuego (Taube, 1988; Chinchilla, 2018; Chinchilla et al, 2015; Tiesler et al, 2013); la relevancia del significado de las antorchas como atributo de poder; los bultos ceremoniales de "fuego"; las ceremonias de los Cuatro Quemadores, $A j$ Tok, relacionadas con los rumbos cardinales y el ciclo de 260 días, (Bernal, 2009a, 2009b). 
Me baso en los datos que aportan los utillajes históricos, monumentos, textos sagrados, pinturas, crónicas y documentos, tomando en cuenta el sitio arqueológico o región a la que pertenecen, así como a su momento histórico y a las trasformaciones que sufren en el transcurrir del tiempo. Las religiones deben estudiarse como realidades que tienen su origen en ámbitos espacio temporales, y acompañan a las distintas coyunturas o conflictos sociales, políticos y culturales; con estos datos es posible realizar analogías y diferencias y así tratar de comprender el sentido original de las acciones rituales, e intentar establecer modelos que se modifican tanto cronológica como espacialmente. Soy consciente de lo mucho que se ha escrito sobre los rituales de fuego en diversas publicaciones, pero a diferencia de otros textos, se intenta conjuntar los datos e interpretar como un todo, en una investigación de largo aliento, la multitud de menciones que encontramos en diferentes textos escritos con diversas finalidades, y presentar la pirolatría de los antiguos mayas desde la perspectiva de la historia comparada de las religiones, disciplina que permite conjuntar y confrontar los datos históricos para intentar ofrecer una interpretación.

Existen algunos verbos como puluyi, “quemarse”, que se utilizan principalmente para acciones hostiles, en especial para devastar ciudades, término que parece derivar de "quemar", pul, pero no pretendo referirme al fuego destructor empleado principalmente en las batallas por no considerarlo un fuego ritual (Scherer y Houston, 2018: 115); no obstante, este verbo lo encontramos en otros contextos como "quemar una cuerda", acción que, como veremos, también alude a un ritual.

\section{Mitos del fuego}

El fuego representó el principio masculino y fecundador del mundo, por ello, para acercarnos a sus valencias, es necesario revisar algunos mitos en donde figura como fecundador del mundo y así comprender sus rituales. En varios textos epigráficos surge como el principio de la creación de un nuevo orden cosmológico, por ejemplo, en un fragmento del Altar 1 [J-P] de Piedras Negras, ${ }^{2}$ relevante sitio arqueológico localizado en la ribera derecha de la cuenca del Usumacinta; el altar fue mandado labrar por K’inich Yo'nal Ahk II (687-729 d.C.) el 15 de marzo del 692, ${ }^{3}$ y se señala que un Sagrado Gobernante mítico es testigo de la sustitución del k'ob',

2 El nombre maya que se ha leído en los datos epigráficos para Piedras Negras es Yokib', “Entrada”. Para agilizar la lectura dentro del texto, cuando se tenga el nombre que los mayas le dieron a una ciudad se incluirá en el aparato crítico.

3 9.13.0.0.0, 8 Ajaw 8 Woh. En este mismo altar, un gobernante de nombre desconocido finaliza el decimotercer k'atun y conmemora su "atadura de piedra”, en 8.13.0.0.0, 9 Ajaw 3 Sak, 14 de diciembre del 297 d.C. (García Juárez, 2016, I: 390). Dado que no es un artículo dirigido en específico a epigrafistas, dentro del texto, para facilidad de lectura, sólo señalaré la fecha en el calendario gregoriano, en tanto que la forma epigráfica que corresponde al b'ak'tun, k'atun, tun, winik y k'in la integraré en las notas a pie de página para el lector interesado. 
el fogón cósmico conformado por tres piedras en la fecha era 13.0.0.0.0, 4 Ajaw 8 Kumk'u, 8 de septiembre del 3114 a.C., ${ }^{4}$ acompañado por los Dioses Remeros, deidades ancestrales que figuran en momentos liminares, y quienes colocaron las tres piedras del fogón, acontecimiento que sucede en el ti’ chan, "en la boca (abertura) del cielo" y "el lugar del Nuevo Fogón” (Velásquez, 2010: 116), que, a decir de García Juárez (2016: 113, 390; 2017: 7-8), sería como un portal celeste que se abre en momentos liminares, y en ho' suuy nal, "el lugar de los Cinco Remolinos" o, de acuerdo con otros autores, en el "Lugar Cinco Flor" (Pitts, 2011: 13-14). Dado el acontecimiento que se narra, la lectura de "el lugar de los Cinco Remolinos" me parece más apropiada porque evoca la evolución de una fuerza, de un estado, propio para un acontecimiento cosmogónico, una rotación creacional y que García Juárez (2017: 7-8) cree identificar con un tramo del Usumacinta. Además, indica que el fuego proviene de un espacio celeste y "el lugar de los Cinco Remolinos" podría simbolizar un quincunce, una imagen del cosmos.

Las tres piedras del fogón se representan con un altar circular que se sostiene por tres soportes y simboliza, de acuerdo con Taube (1998: 427), el fogón de la creación, que se caracteriza con un jeroglífico de tres cuentas de jade y se localiza tanto en el hogar como en los templos; es otra de las imágenes del centro del mundo, y colocada en cada uno de los rumbos cardinales sería el lugar en donde se levantarían los cuatro árboles cósmicos, se establecería además un espacio para conjurar y comunicarse con lo divino, a través de la ofrenda de sangre, copal y otras sustancias; el autor agrega que es precisamente en el "lugar del Nuevo Fogón” y que por ello se utilizaría como un símbolo para la fundación de un territorio nuevo o bien los orígenes de una dinastía (Figura 1).

No lejos de Piedras Negras, en las tierras bajas centrales, en Palenque, ${ }^{5}$ en un fragmento del texto del Tablero del Templo de la Cruz [D3-C8] dedicado en el 692 d.C. ${ }^{6}$ (y que curiosamente coincide con el año en el que fue mandado labrar el Altar 1 de Piedras Negras), se cita el mismo mito de creación durante el cual se reemplaza el k'o'b', "fogón de tres piedras», en el Nuevo Lugar del Fogón en la Orilla del Cielo (el horizonte) por orden de Wak Chan Ajaw, "Gobernante Seis Cielo" (Bernal, 2011: 460).

Otra versión de este mito se reitera en la multicitada Estela C de Quiriguá, ciudad ubicada cerca del río Motagua, en Izabal, Guatemala; el monumento lo consagra K'ahk' Tiliw Chan Yopaat (724-785 d.C.) el 25 de diciembre de 775 d.C., 7 y cuenta con detalle la creación del mundo:

\footnotetext{
${ }^{4}$ Otros autores utilizan el 13 de agosto de 3114 a.C. debido a que no contemplan la reforma del calendario gregoriano, impuesta por el papa Gregorio XIII en el 1582, y continúan empleando las del juliano, que se utilizaba desde Julio César.

${ }^{5}$ El antiguo nombre de Palenque fue Lakamha', "Aguas Grandes".

${ }^{6}$ Uno de los principales acontecimientos que se celebran en este tablero fue el ascenso de K'inich Kan B'ahlam II en el momento de ascender al trono el 7 de enero de 684 d.C., 9.12.11.12.10, 8 Ok 3 K'ayab'.

7 9.17.5.0.0, 6 Ajaw 13 K'ayab'. La creación a partir de la Fecha Era también se cita, entre otros monumentos, en la Estela 1 de Cobá, y en un 4 Ajaw en una máscara de Río Azul, en el Vaso de los Siete Dioses de Naranjo y en Copán, pero no se alude al fuego como el elemento central.
} 


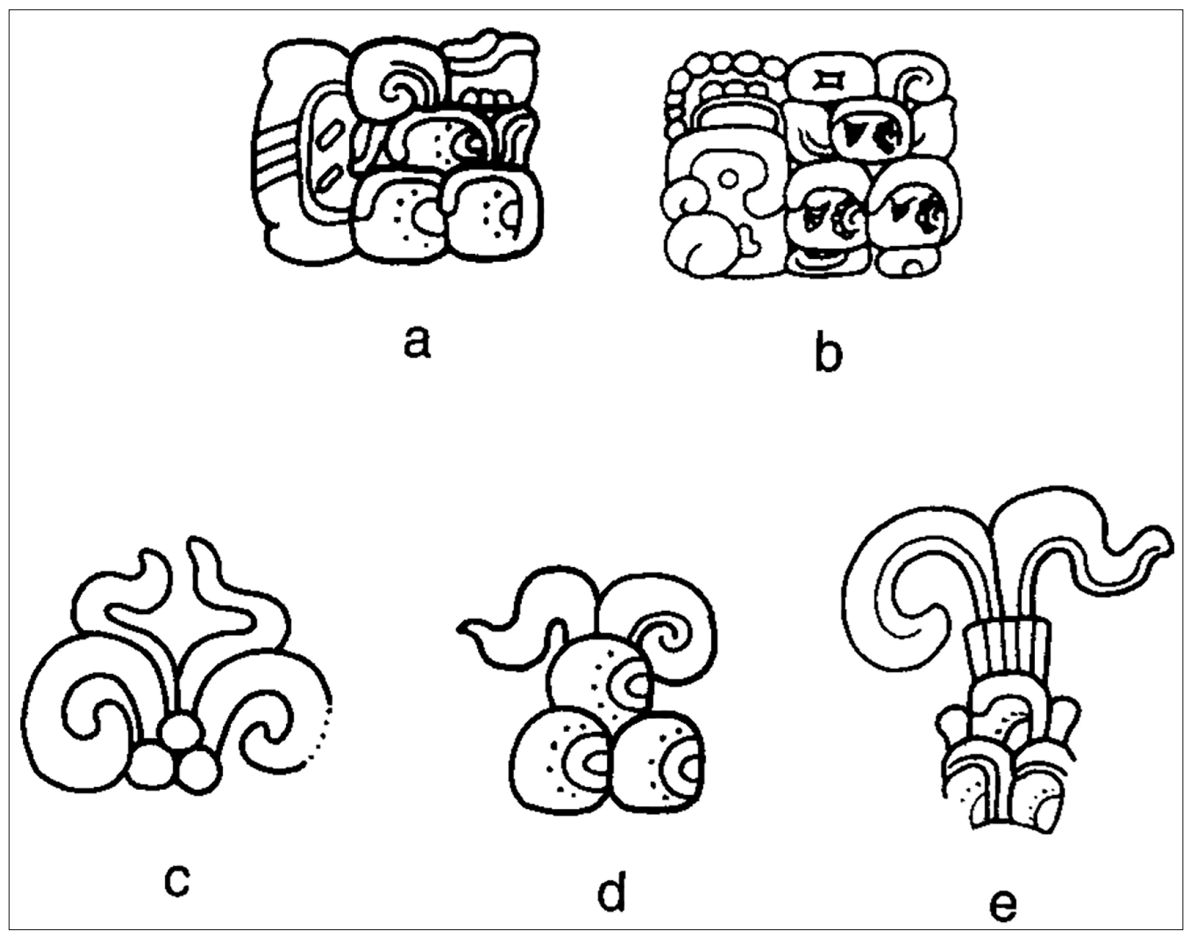

Figura 1. Las tres piedras del fogón en el Clásico maya: a) Estela de Quiriguá; b) Jeroglífico emblema de Ceibal, tablero 4; c) Tres piedras humeantes, Monumento 74, Toniná; d) Piedras humeantes sobre el tocado de regente de una estela de Toniná; e) Tres piedras con madera quemando, Estela 30 de Naranjo (Taube, 1998: 435).

[En la fecha] 13.0.0.0.0, [en el día] 4 Ajaw 8 Kumk'u [13 de agosto de 3114 a.C.] el fogón fue sustituido. Las tres piedras fueron atadas. Los dioses remeros hincaron la piedra, ocurrió ya en Naah Ho' Chan [Primer Cinco Cielo]; la piedra del trono jaguar. Ik' Naah Chak ... hincó la piedra, ocurrió ya en Kab' Kaaj; la piedra del trono tiburón. Entonces ocurrió la atadura de piedra de Naah Itzam Kohkaaj Muut, la piedra del trono de agua. Ocurrió ya [en] el borde del cielo, el sitio del primer fogón. Trece b'aktuunes se terminaron. Wak Chan Ajaw lo ha ordenado (Vega, Aguirre y Crasborn, 2012: 1052).

Con esta acción se reordenan los tres estratos cósmicos a través de la tríada pétrea que, de acuerdo con el mito de Quiriguá, no solo significa los estratos cósmicos, sino también funciona como el "fogón inicial" desde donde se vuelve a encender el gran fuego cósmico. Velásquez $(2006: 113,136)$ agrega que es como el fogón de la cocina que constituye el corazón de una choza, porque los mayas concebían al universo como una gran casa. El mismo fundador de Quiriguá, Tok “Casper” y su sucesor K'ahk' Tiliw Chan Yo’aat, igualan el acto de instituir su casa 
dinástica con los acontecimientos que dieron origen al cosmos, como fue atar las tres piedras cósmicas que forman el fogón. Llama la atención tanto la distancia en el tiempo como geográfica con los dos mitos anteriores, lo que nos habla de una cosmogonía común en la que el elemento ígneo asume un papel primordial.

Es relevante subrayar que en los ejemplos citados ya exista un fogón original y éste se vuelva a encender; por lo tanto, parecería que el fuego siempre existió, y cada vez que se reitera esta acción se recrea la cosmogonía y marca un momento liminar, de transición entre un periodo y otro, el tiempo mítico y el humano, por ello el fuego es liminar por excelencia. Por otro lado, de acuerdo con la mitología palencana, como lo señala el pasaje cosmogónico de la plataforma del Templo XIX de Palenque, dedicada por K'inich Ahkal Mo' Nahb' el 10 de enero del 734, ${ }^{8}$ se asienta que GI, quien entre otros epítetos recibe el del "Dios del Fuego Nuevo", causa una inundación de sangre al decapitar un cocodrilo en el 3298 a.C., y luego taladra el fuego para formar un nuevo orden cósmico (De la Garza, Bernal y Cuevas, 2012: 227). Por ello, se podría suponer que ese es precisamente el fuego original de la cosmogonía y que con posterioridad se vuelve a encender el $k^{\prime} o^{\prime} b$ ', el "fogón de tres piedras" en el inicio de la llamada Fecha Era en el 3114 a.C. Además, resulta significativo que la casa de GI en el Templo XIX se llamaba "la Casa de los Ocho Quemadores (Incensarios) del Sol, la Casa del Basamento (?) del Fuego", "El Dios del Fuego Nuevo" Yax K'ahk' K'uh (Bernal Romero, 2006: 90, 219-220), un dios creador por excelencia.

Quizás en las excavaciones realizadas por Inomata y Triadan $(2015: 68,86)$ en Ceibal, Guatemala, las tres piedras calizas de forma esférica, de aproximadamente $15 \mathrm{~cm}$ de diámetro, ubicadas en el Depósito 129 y datadas para el Preclásico Medio, pudieron conformar aquel fogón divino citado por Taube (1998: 427), de aquí que probablemente aludieran a la fundación de Ceibal y se reiterara el momento prístino de la creación al taladrar el fuego original.

\section{Ceremonia para taladrar el fuego}

En los datos epigráficos, de acuerdo con Grube (2000: 93-99, 105), existen diferentes formas de expresar el encendido del fuego que se incluyen en las Series Iniciales: tihl k'ahk, "prender", "quemar", "iluminar" o "fuego de luz", "ardiente en llamas"; jatz' k'ah'k' K'inich Ajaw, "este es el fuego por golpe del Dios del Sol”; puuk k'ahk', pukil k'ahk', "dispersión del fuego"; puluuy k'ahk', "prender fuego". García Barrios y Velásquez (2018: 104-104) también citan el logograma EL, que puede significar "quemar" cuando se acompaña del determinativo semántico de las flamas, como el logograma TIL, "quemar", de tal forma que indica una acep-

\footnotetext{
8 9.15.2.7.16, 9 Kib' 19 K'ayab'.

${ }^{9}$ Grube (2000: 103-104) encontró el encendido de fuego en las Series Iniciales en 35 monumentos fechados y en seis sin fechas.
} 
ción vinculada con las flamas. No obstante, la más frecuente es el encender el fuego sagrado con una barrena, joch' k'ahk', "taladrar el fuego" (Grube, 2000: 93-99); este último texto jeroglífico ha sido estudiada a su vez por Stuart (1998: fig. 21; 2010: 34, 76), ${ }^{10}$ quien muestra diversas variantes localizadas en múltiples sitios (Figura 2). Elegiré unos cuantos ejemplos significativos en los que funciona, entre otros motivos, como marcador calendárico, como los que cita puntualmente Bernal (2016: 122) con motivo de las ceremonias en el factor calendárico del ciclo de 63 días, resultado de multiplicar 7 x 9; ${ }^{11}$ no obstante, los mayas, como se verá, lo hicieron coincidir con otras fechas significativas y diferentes deidades. Esta selección responde a que se muestra con claridad el significado del fogón en el citado ciclo.

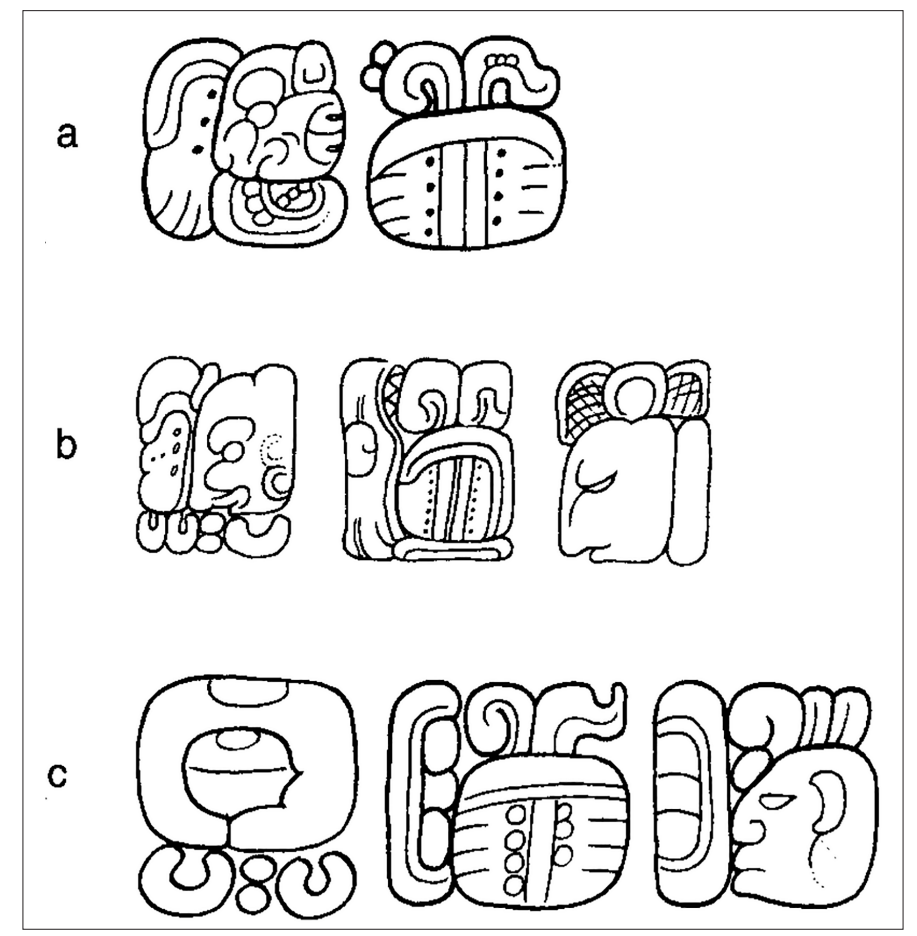

Figura 2. Joch' k'ahk', "se taladra el fuego", a) Dintel sin procedencia; b) Yaxchilán, Dintel 29; c) Yaxchilán, Estela 1 (Stuart, 1998: fig. 21).

${ }^{10}$ Barthel, citado por Stuart (2010: 76), señala que en 1955 se mencionaba el "barrenado de fuego" en las inscripciones de Chichén Itzá. A veces, según este autor, figura con el sufijo -aj que podría tratarse como la "entidad perforadora/encender de fuego".

${ }^{11}$ Se conocían otros, de 7, 9, 13 y 819 días. El de 63 días es el resultado de multiplicar los dos primeros $(9 \times 7=63)$, y el tercero, de multiplicar esta última cifra por $13(63 \times 13=819)$. Para más información sobre este ciclo, véase Bernal, 2016. 
Inicialmente lo descubre en el Tablero Este [C-5D-5] del Edificio 1 del Grupo XVI de Palenque el 28 de mayo del $673^{12}$ y lo relacionó con el periodo sinódico de Saturno, de 378 días, que es de seis veces este ciclo. Asimismo, es parte del ciclo de 819 días $(7 \times 9 \times 13) .{ }^{13}$ Los textos sobre el encendido de este fuego tienen otros elementos interesantes, como que fue dedicado a una deidad o es poseído por el dios Pawaaj Sahb'iin, “(dios) Pawaj-Zariguieya” (Didelphys marsupialis), ${ }^{14}$ una manifestación zoomorfa del anciano Dios N, Pawaajtun, y por la relación que comprueba del ciclo de 63 días con Saturno sería a su vez una deidad saturnina ${ }^{15}$ (Bernal, 2016: 111-118, 122) (Figura 3). Es preciso tomar en cuenta la relevancia de este dios que, de acuerdo con Martin (2015: 192, 226), al recapitular lo dicho por otros autores, considera que representa el centro de la tierra, así como el cielo y las cuatro regiones cósmicas, por lo tanto, tiene una forma cuadripartita, separa el cielo de la tierra, lo liga a su vez a las primeras aguas y pertenece al grupo de dioses ancianos, creadores y sustentadores; por ello no es de extrañar que figure en diversos actos rituales como el que posee o a quien le dedican el fuego.

Continuando con la búsqueda del ciclo de 63 días, Bernal (2016: 116-118) localiza el joch' k'ahk' en diferentes sitios y comprueba su continuidad y que cada uno está vinculado con un múltiplo exacto y solidario de este ciclo. Así, cita los Dinteles 29 y 30 de Yaxchilán ${ }^{16}$ [C5 -D5] (Graham y Von Euw, 1977) ${ }^{17}$ ciudad ubicada en el margen occidental del río Usumacinta, en la que se registra el nacimiento de Yaxuun B'ahlam IV el 23 de agosto de 709 d.C. y seis días antes, el 17 de agosto, se "taladró el fuego" una vez más para Pawaaj Sahb’iin; podría preguntarme si era para magnificar el nacimiento del heredero, porque además hubo un ritual relacionado con K'awiil un día después de encender el fuego y esta deidad tiene entre sus atributos el fuego (Cuadro 1).

Resulta de especial interés el Panel 2 de Laxtunich (Jackson, 2013: 133, fig. 42), sitio subsidiario de Yaxchilán, porque en la escena se muestra el momento

12 9.12.1.0.5, 6 Hix 17 Tzek.

${ }^{13}$ De acuerdo con Voss (2001: 139) el ciclo de 819 días "corresponde estructuralmente al ciclo de los portadores del año con el cambio ininterrumpido de los cuatro puntos cardinales y colores correspondientes."

${ }^{14}$ En diversos mitos mesoamericanos, la zariguieya o tlacuache es quien roba el fuego para los hombres, como ha sido ampliamente tratado por López Austin (1996: 293), quien agrega que es también quien roba “...el maíz, el aguamiel, el pulque, el tabaco y el mezcal, pero además figura como creador del tiempo y roba los flujos frío y caliente del cosmos para llevarlos a los cuatro postes de los que se derramarán en beneficio de los hombres".

${ }^{15}$ La fecha elegida para este ritual fue 31 días antes de la Cuenta Larga, en 9.12.00.16.14, 6 Hix 17 Tzek, 28 de mayo de 673 d.C.

16 Vega (2017: 63) sugiere que el antiguo nombre de Yaxchilán fue Tahn Ha’Pa'chan, “Cielo Hendido [en el centro del agua]", en tanto que su linaje era Pa'chan, "Cielo Hendido".

17 Los Dinteles 29, 30 y 31, ubicados en los tres vanos de la Estructura 10, integran un solo texto (Stuart, 1998: 387) que evoca no solo el nacimiento de Yaxuun B'ahlam IV y la fecha en que asciende al poder, sino también la conmemoración del edificio y el final de un k'atun en curso. 


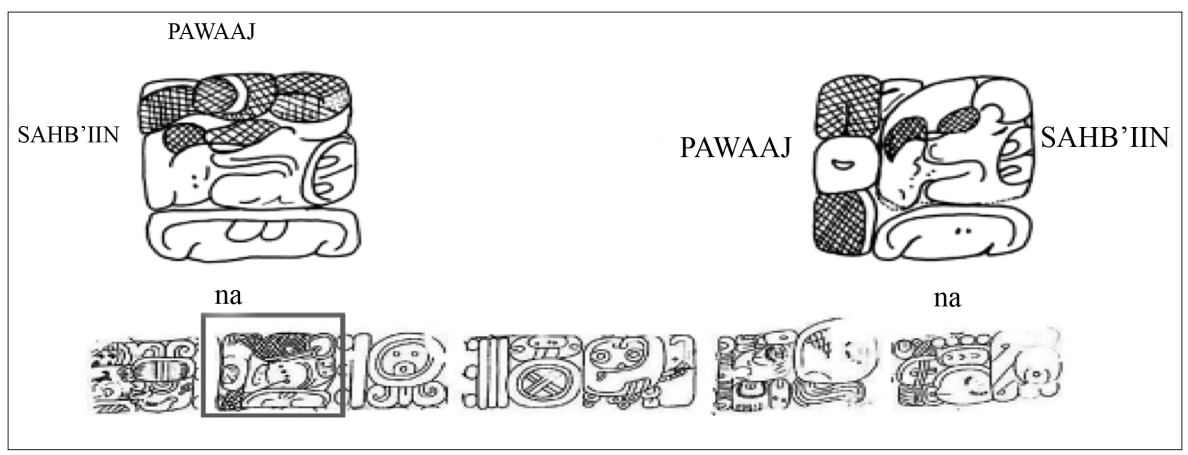

Figura 3. PAWAAJ-SAHB'IIN-na, Pawaaj Sahb'iin

(Bernal, 2016: 112, fig. 1; 2014a: 71).

\begin{tabular}{|l|l|l|l|l|}
\hline \multicolumn{1}{|c|}{ Monumento } & \multicolumn{1}{|c|}{ Cuenta Larga } & Fecha juliana & Deidad & Acontecimiento \\
\hline $\begin{array}{l}\text { Tablero Este } \\
\text { del Edificio 1 del } \\
\text { Grupo XVI } \\
\text { de Palenque }\end{array}$ & $\begin{array}{l}(9.12 .0 .16 .14) \\
\text { 6 Hix 17 Tzek }\end{array}$ & $\begin{array}{l}28 \text { de mayo de } \\
673 \text { d.C. }\end{array}$ & Pawaaj Sahb'iin & \\
\hline $\begin{array}{l}\text { Dinteles 29 y } \\
\text { 30 de Yaxchilán }\end{array}$ & $\begin{array}{l}(9.13 .17 .12 .9) \\
2 \text { K'an 7 Yax }\end{array}$ & $\begin{array}{l}17 \text { de agosto } \\
\text { de } 709 \text { d.C. }\end{array}$ & Pawaaj Sahb'iin & $\begin{array}{l}\text { Texto que conti- } \\
\text { núa en el Dintel } \\
\text { 30 y conmemora } \\
\text { el nacimiento de } \\
\text { Yaxuun B'ahlam* }\end{array}$ \\
\hline $\begin{array}{l}\text { Panel 2 } \\
\text { de Laxtunich }\end{array}$ & $\begin{array}{l}(9.16 .18 .0 .19) \\
1 \text { Kawak 2 Woh }\end{array}$ & $\begin{array}{l}18 \text { de febrero } \\
\text { de } 769 \text { d.C. }\end{array}$ & & \\
\hline
\end{tabular}

* Las fechas que ofrecen los epigrafistas, a veces no coinciden por algunos días, por ejemplo, Lacadena (2004: 92) señala que fue el 9.13.17.12.10, 8 Ok 13 Yax, que equivaldría al 27 de agosto de 709 d.C. No obstante, para nuestros fines no implica gran diferencia.

Cuadro 1. El ritual joch' k'ahk', “taladrar el fuego”, y el ciclo de 63 días (Tomado de Bernal, 2016: 115-117 y modificado por la autora).

en que el sagrado gobernante de Yaxchilán, Itzam B'ahlam Chelew Chan K'inich, ${ }^{18}$ "taladra el fuego" [A2- B2], el 18 de febrero de 769 d.C. ${ }^{19}$ El personaje que tiene frente a él es el joven sajal K'uhul U Kan, quien lleva el título de B'aah Wahyib', “Nahualista Principal”, y sostiene el cartucho glífico ch'ab' ak'ab' “creación (en la oscuridad)"; los dos personajes están sentados sobre Sak B’aak Naah Chapaat, "Ciempiés de la Casa de los Huesos Blancos" (Bernal, 2014a: 68; 2016: 117). De

${ }^{18}$ Este personaje es hijo del famoso mandatario Yaxuun B'ahlam IV.

19 9.16.18.0.19, 1 Kawak 2 Woh. 
acuerdo con Sheseña, el ritual se lleva a cabo en el interior de una cueva, figura la sumisión o alianza entre las entidades participantes y se ratificaba la preeminencia de un orden político; de aquí deduce que la posesión del fuego era de suma relevancia gubernamental, porque denotaba una superioridad. En este ejemplo, al ser el encendido de fuego nuevo en una caverna, se trataba de un evento de (re)fundación (Sheseña, 2005: 93-94; 2015: 76, 132), o bien indicaba que se "tomaba asiento" del sitio. Habría que subrayar que cuando el gobernante vuelve a encender un fuego, a crear en la oscuridad, $c h^{\prime} a b^{\prime} a k^{\prime} a b^{\prime}$, remite a la regeneración de un hecho mítico, de un fragmento de la cosmogonía y asume el papel de una deidad creadora (Figura 4).

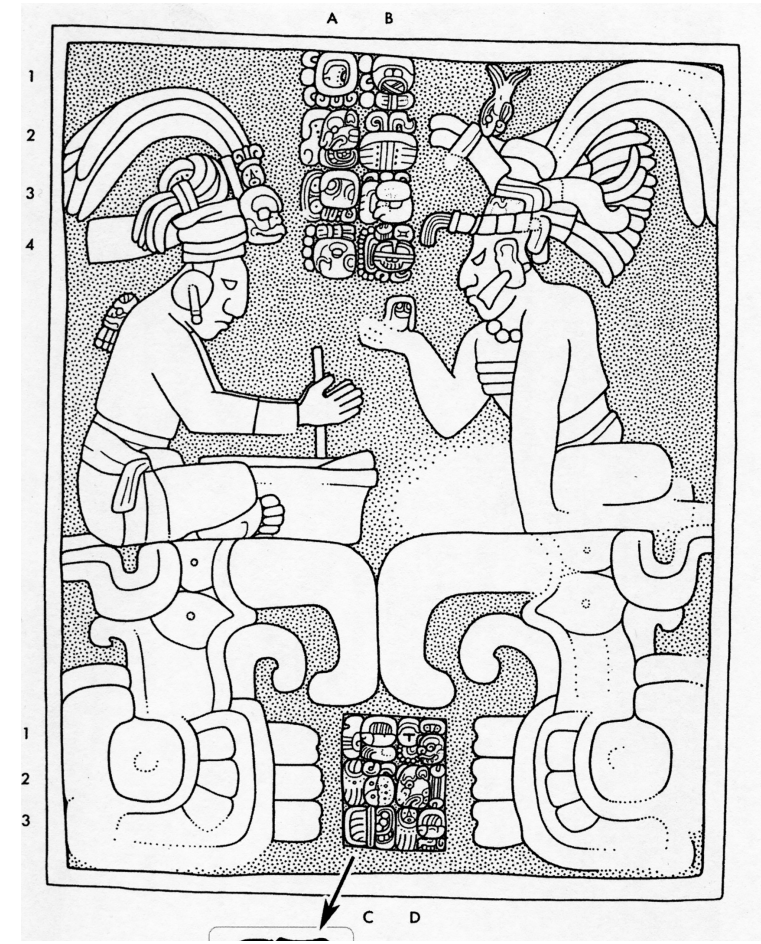

Figura 4. Panel 2 de Laxtunich, A2, B2

(Dibujo de Mathews, tomado de Bernal, 2014: fig. 6).

En la Estela 1 de Motul de San José, el Sitio Ik', ubicado en la región del lago del Petén Itzá o Chaltunhá, se utilizó una forma variante del rito, tihl k'ahk', "prender o encender el fuego", "iluminar"; desconozco si la técnica para encender el fuego era diferente, solo sabemos que también describe un acto de quemar y es un fuego que pertenece a ciertas deidades (Scherer y Houston, 2018: 116), en este caso de Yax Xib' Chaahk, deidad vinculada con el rayo y por ende con el fuego; ahora bien, el producto de esta ignición parece tener la finalidad de ser 
una fuente de calor, iluminación, energía sagrada, como las flamas sagradas que se mantienen en algunos templos. Al mismo tiempo se conmemora la investidura del sagrado gobernante de Ik', Yexte' K'inich. La ceremonia tuvo lugar el 5 de marzo de 701 d.C. ${ }^{20}$ lo cual reitera que el ritual ígneo no sólo era un marcador de tiempo, sino que se utilizaba también en el ascenso de un mandatario (Bernal, 2016: 117-118), porque formaba parte de sus rituales de iniciación en los momentos más relevantes de su vida, era un periodo liminar necesario para adquirir la dignidad requerida para el cargo, y así cada nuevo gobernante tenía la posibilidad de participar en la regeneración del cosmos, de crear un tiempo pasado y unirlo a un tiempo nuevo; provoca al mismo tiempo la continuidad y la discontinuidad.

En el norte de Yucatán y a finales del Clásico tenemos dos ejemplos en Ek' Balam, en el mural del Cuarto 22 de la Estructura 1 (Acrópolis). El 18 de octubre del 783 d.C. ${ }^{21}$ hubo una ceremonia vinculada con el fuego que ocurrió en "una casa", ti otoot, suponemos un templo (Lacadena, 2003: 64, fig. 22a), con lo que ese espacio se purificaba y sacralizaba, tal ejemplo debe vincularse con la "entrada del fuego" que veremos más adelante. El otro ejemplo de la ceremonia joch'ool k'ahk' proviene de la Columna 1, que se erige en el Nivel 3 de la Acrópolis, al término del décimo b'ak'tun, ${ }^{22}$ el 11 de marzo de 830 d.C.; de acuerdo con Lacadena (2003: 20, fig. 5b, Columna 1, Texto 2J4), se rememora la colocación de la columna, a la que llaman sak ahk b'aahil tuun, "ila imagen de la tortuga blanca de piedra?"23 auspiciada por Ukit Kan Le'k, gobernante de Talo'l, y una vez más se vincula con el dios Pawaaj Sahb'iin", aunque el ciclo de 63 días se conmemoraría un día después, el 12 de marzo ${ }^{24}$ no obstante, es sugestiva la carga de sacralidad que adquiría el monumento y por ende el grado de veneración que debió recibir.

Por otro lado, estos registros resultan relevantes no sólo porque se vuelve a citar al mismo dios en lugares tan distantes para la misma ceremonia, sino después de más de 120 años, lo que nos muestra un núcleo base de pensamiento en las diferentes comunidades mayas. En este caso se utiliza la expresión p'ulil, "sahumerio", seguida de k'ahk' (Bernal, 2016: 118-120).

De hecho, en los dos ejemplos de Ek' Balam, se trata de fundaciones, creando un antes y una después, se le otorga vida al Templo 22 y se conmemora el final

20 9.13.9.1.17, 9 Kab'an 0 Woh.

21 9.17.12.16.14, 13 Hix 7 K'ank'in. De acuerdo con Lacadena (2003: 67), el texto del mural del Cuarto 22 aporta evidencias "sobre la realización de una ceremonia de pronosticación de un 14 tuun k'ay[il] asociada a los rituales de Año Nuevo, como las que describe Landa...”.

22 10.0.0.0.0, 7 Ajaw 8 Sip.

${ }^{23}$ Lacadena la traduce como la "tortuga galápago"; no obstante, en Yucatán, de acuerdo con el Diccionario Maya Cordemex, se han registrado seis familias de tortugas, 13 géneros y 14 especies, por ello es muy difícil definir a qué tortuga se refiere. A solicitud de uno de los dictaminadores del artículo incluyo la traducción.

${ }^{24}$ 10.0.0.0.1, 8 Imix 19 Sip, Bernal (2016: 118-120) aclara que la expresión que aparece es "está taladrado el fuego", por lo que el "Ciclo-63" si bien ocurriría un día después para conmemorar el final del b'ak'tun, se llevó a cabo un día antes de la fecha término. 
de otro tiempo, un b'ak'tun, con la inauguración de la Columna 1, y además lo hacen coincidir con un ciclo más de 63 días (Cuadro 2).

\begin{tabular}{|c|c|c|c|c|}
\hline Monumento & Cuenta larga & FECHA JULIANA & DeIDAD & ACONTECIMIENTO \\
\hline $\begin{array}{l}\text { Estela } 1 \text { de Mo- } \\
\text { tul de San José }\end{array}$ & $\begin{array}{l}(9.13 .9 .1 .17) \\
9 \text { Kab'an } 0 \text { Woh }\end{array}$ & $\begin{array}{l}5 \text { de marzo } \\
\text { de } 701 \text { d.C. }\end{array}$ & $\begin{array}{l}\text { Yax Xib' } \\
\text { Chaahk }\end{array}$ & $\begin{array}{l}\text { Vinculado con } \\
\text { un rito tihl } \\
\text { k'ahk', "Prender } \\
\text { o encender el } \\
\text { fuego". } \\
\text { Entronización } \\
\text { de Yejte' K'inich, } \\
\text { como Sagrado } \\
\text { Gobernante } \\
\text { de Ik' }\end{array}$ \\
\hline $\begin{array}{l}\text { Mural del Cuar- } \\
\text { to } 22 \text { de Ek' } \\
\text { Balam }\end{array}$ & $\begin{array}{l}(9.17 .12 .16 .14) 13 \\
\text { Hix } 7 \text { K'ank'in }\end{array}$ & $\begin{array}{l}18 \text { de octubre } \\
\text { de } 783 \text { d.C. }\end{array}$ & & $\begin{array}{l}\text { Ocurrió “en una } \\
\text { "casa” (ti otoot) }\end{array}$ \\
\hline $\begin{array}{l}\text { Columna } 1 \text { de } \\
\text { Ek' Balam }\end{array}$ & $\begin{array}{l}(10.0 .0 .0 .0) 7 \text { Ajaw } \\
18 \mathrm{Sip}\end{array}$ & $\begin{array}{l}11 \text { de marzo } \\
\text { de } 830 \text { d.C. }\end{array}$ & $\begin{array}{l}\text { Pawaaj } \\
\text { Sahb'iin } \\
\text { joch'ool k'ahk', } \\
\text { "está taladra- } \\
\text { do el fuego } \\
\text { del dios Pawa- } \\
\text { aj Sahb'iin" }\end{array}$ & $\begin{array}{l}\text { Final de un } \\
\text { b'ak'tun. } \\
\text { Colocación de } \\
\text { la propia columna, } \\
\text { llamada sak ahk } \\
\text { b'aahil tuun, } \\
\text { "¿La Imagen de } \\
\text { la tortuga blanca } \\
\text { de piedra?” }\end{array}$ \\
\hline
\end{tabular}

Cuadro 2. El ritual de encender el fuego y el ciclo de 63 días (Bernal, 2016: 117-120, modificado por la autora).

Los registros más tardíos de este ciclo vinculados con el encendido del fuego que se han localizado pertenecen a la banda de jeroglíficos de la Casa Colorada de Chichén Itzá (Figura 5) que marcan el principio de más de 120 años de historia escrita de dicha ciudad. En este caso se señalan dos ceremonias de barrenado del fuego y suceden en una cuenta secuencial de tunes, el 11 de septiembre, un día después del "Ciclo-63" en el año de 869 d.C. (Bernal, 2016: 118), ${ }^{25}$ y se les

25 10.2.0.1.9, 6 Muluk 12 Mak. Según Grube y Krochok (2011: 164) equivale al 5 de septiembre de 869 d.C., fecha con la que inicia la banda de jeroglíficos. De acuerdo con García Campillo (1999: 149) el 11 de septiembre de 869 d.C. en la Casa Colorada [5-9] fue encendido un fuego por Yax $u$ k'u... K'awiil, y agrega que hubo otros eventos asociados a la misma, como son el taladrado o frotado del fuego, por Te u chock [13-16], y K’ak’upakal experimentó una visión [20-26]. 
dedican a dos dioses regionales. En los jeroglíficos 13 y 14, de acuerdo con Grube y Krochock (2007: 165, fig. 8), se lee: joch'b'iiy u k'ahk', 'fue taladrado el fuego de...". Resulta significativo que en la inscripción continúa un conjuro de una visión que tuvo lugar "... en el sol, en el agua y entre los lirios acuáticos (?)" por K'ak'upakal, el individuo más relevante citado en el texto [1-19]; la lectura podría sugerirnos que estas ceremonias de fuego eran para que el gobernante pudiera lograr visiones o tal vez "revelaciones" divinas y "sumergirse" en los diferentes ámbitos cósmicos. La segunda parte de la inscripción se introduce por una fecha nueva, 6 de junio de 870 d.C. ${ }^{26}$ y se agrega una afirmación también vinculada con el fuego; pu-lu-ji-ya ti-k'a-k’a jo-?-la, "y entonces el/esto se quemó como un fuego en jo...l?" ; además se ubica en una locación, porque los dos siguientes bloques de jeroglíficos u-ti-ya ?-?-jo-lo, "esto sucedió en ...jol", quizá se trate de un templo de Chichén Itzá. El texto continúa con una cuenta secuencial de tunes (Grube y Krochok, 2011: 164-166, figs. 8 y 9):

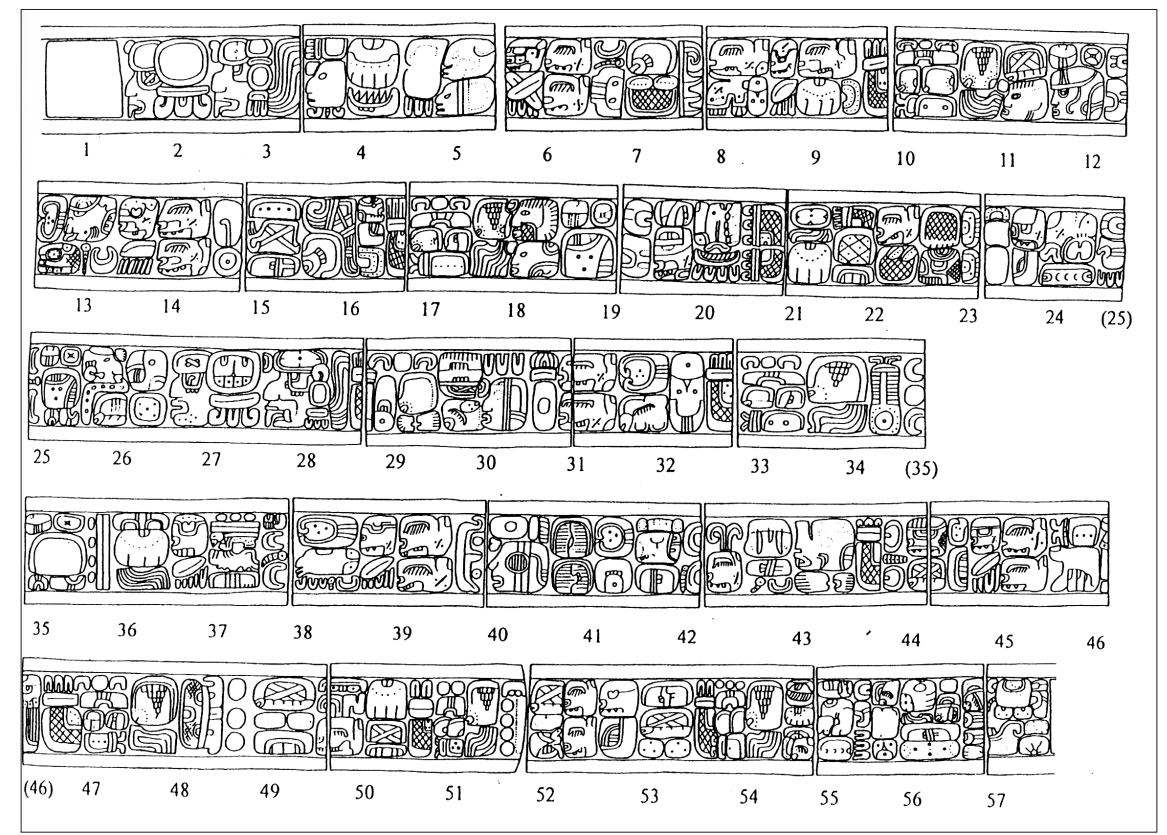

Figura 5. Banda de jeroglíficos de la Casa Colorada de Chichén Itzá, 13-14, joch'b'iiy u k'ahk', "es el taladrado de fuego de...".

(Dibujo de Alexander Voss, tomado de Grube y Krochock, 2011: 165, fig. 8).

Se menciona a los dioses, u k'ab'a' k'uh, "el nombre del dios", A'yax'u k'uk'um K'awiil, "Verde es la pluma de K'awiil” (Boot, 2005), o según otros autores, Yax

26 10.2.0.15.3, 7 Ak'b'al 1 Ch'en. 
U K'uk'um? K'awiil y ¿u-cho-ki? (Grube, Lacadena y Martin, 2003) y se invoca a una divinidad más (?); K’awii, la "personificación" del rayo, el fuego celeste. La relevancia del ritual se demuestra porque los tres personajes que supervisan la secuencia de eventos ígneos son todos señores que tienen la categoría de k'uhul: el gobernante de Ek' Balam, K'inich Ju'npik To'k', el de Chichén Itzá, K'ak'upakal K'awiil, y el que parece era su hermano, Kokom Yajawal ..., dato que junto con otros hechos registrados indica que Chichén Itzá en una fase temprana estuvo bajo la hegemonía de Ek' Balam, y quizá estos rituales fueran la manera de reconocer la supremacía de esta ciudad por la asistencia de su gobernante a testificar un evento tan solemne y relevante (Grube y Krochock, 2011: 165-167). La última fecha registrada para encender el fuego en el "Ciclo-63" es el 3 de enero de 874 d.C. ${ }^{27}$ en el Dintel 1 de Yulá, asentamiento ubicado a $5 \mathrm{~km}$ de Chichén Itzá.

Hasta aquí he expuesto las ceremonias que conmemoraban el "Ciclo-63" pues permiten encontrar una clara continuidad y periodicidad; no obstante, existen multitud de ceremonias de encendido de fuego en las inscripciones mayas que se llegan a encontrar en diversos tipos de edificaciones; a manera de ejemplo, cito las que se evocan en la Escalera Jeroglífica 1 de Cancuén, de carácter calendárico, y que se realiza en Machaquilá, sitios del periodo Clásico localizados en el Petén guatemalteco; Lacadena (2003: 218, 229-230, n. 24) lo comprueba por las lecturas que señalan que durante los años en que Machaquilá estuvo bajo el dominio de Cancuén se celebraron dos rituales de fuego: ${ }^{28}$ uno de ellos lo presidía un personaje que incluía el jeroglífico del número 6 y el título de ajaw (Fashen, Demarest y Luin, 2003: 708-710, figs. 9 y 10). Es obvia la relevancia política que revelan dichas ceremonias, y a diferencia de la citada en Chichén Itzá, en este caso se desarrollan en Cancuén, la ciudad dominante, lo que indica diferencias y además que la hegemonía incluía también la esfera de lo religioso. Lacadena sugiere también que se llevaron a cabo alrededor del 786 d.C. y que podría existir una relación entre estos rituales de fuego y los de ahtoc [Aj Tok], "los quemadores" citados en los libros del Chilam Balam y que se asocian a las fechas 4 Ok, 4 Men, 4 Ajaw, 4 Chikchan, en las que se conmemoraban ciclos de 365 días; en Machaquilá, agrega, la celebración de este ciclo cae precisamente en tres de los cuatro días de esta serie y podría asociarse a un ciclo recurrente de $3 \times 365$ días.

Otra referencia es la Estela 1 de Ek' Balam (Lacadena, 2003: 6-12, fig. 2b: [A8$\mathrm{B} 8]$ ) en la que la ceremonia ígnea tiene lugar el 18 de enero de 840 d.C., ${ }^{29}$ y se consagra la erección del monumento bajo el auspicio del kalo'mte'30 Ukit Kan Le'k, el mismo gobernante que diez años antes se cita en la Columna 1, y cuya figura se aprecia en la parte frontal de la Estela 1. Señala Lacadena, "el hincó (es decir, erigió) el "Ajchan Naah", (que) es el nombre de la estela»; de acuerdo

27 10.2.4.8.4, 8 K'an 2 Pohp un día después de la "estación-63".

28 9.17.5.6.6, 2 Kimi 14 Tzek y en 9.17.15.4.14, 8 Ix 13 Pop.

${ }^{29}$ 10.0.10.0.0, 6 Ajaw 10 Pop.

${ }^{30}$ El título de kalo'mte' solo fue ostentado por los más importantes gobernantes sagrados de los mayas del periodo Clásico y se restringía a los dignatarios que tuvieran otros k’uhul ajaw subordinados. 
con ello, me parece que a la construcción de un nuevo elemento arquitectónico relevante se le daba vida con el encendido de un fogón y al darle un nombre al monumento adquiría una particularidad peculiar.

En suma, considero que este ritual, que con seguridad formaba parte de una ceremonia más compleja, y que tenía el propósito de originar un fuego nuevo, se lograba con el frotamiento de un elemento masculino, madero de punta aguzada, en un recipiente cóncavo, el elemento femenino, que contenía residuos de madera y hojas secas; el "palillo macho" giraba alternativamente en uno u otro sentido provocando un calentamiento, hasta que se engendraba la codiciada flama.

Por las características del ritual considero que podría interpretarse como un acto de fecundación; es la forma de regenerar el mundo, de recrear el mito cosmogónico y cada vez que se llevaba a cabo este acto se creaba un "fuego nuevo". Por ello se registró en diferentes momentos, generalmente asociado al fin de un ciclo y el principio de otro, porque el tiempo también se agota y es preciso revitalizarlo recurriendo al elemento original de la creación; el fuego está presente en momentos liminales, de ahí que figure en los diferentes eventos de la vida de un gobernante, su nacimiento, cuando asciende al poder, la fundación de una dinastía; o bien al erigirse una nueva columna, dedicar una escalera, una estela, un monumento o al clausurar una construcción, es decir, en momentos delicados de cambio en la sociedad, coyunturas en las que se necesita celebrar y reforzar a las fuerzas de la naturaleza. Por ello, no es extraño que se encendiera al celebrar el triunfo de una nueva conquista y la posesión de un territorio, porque el fuego señala momentos fundamentales para la historia de un pueblo. En el centro de México, agrega Olivier (2010a: 297-301; 2010b: 57), también se encendía cuando se abandonaba el lugar de origen, porque la gente se transformaba al pasar de un lugar a otro, y no sólo cuando se construía un nuevo templo sino al fundarse una ciudad.

\section{El fuego en las cuevas}

Las cuevas fueron un sitio sagrado y una entrada al inframundo, de ahí la multitud de restos de ceniza que han encontrado los espeleólogos, porque eran sitios ideales para una ceremonia de fuego, seguramente con la quema de ofrendas. Ya señalé algunas referencias al referirme al Panel 2 de Laxtunich en el que dos nobles crean el fuego en una cueva. Sheseña (2005: 91-103; 2015: 132-133), desde otra óptica, analiza las ceremonias ígneas que se muestran en textos jeroglíficos. Entre ellas el autor estudia la Pintura 82 [A-2] de la cueva de Naj Tunich, Guatemala, datada para el Clásico Tardío, a donde acudían sacerdotes y gobernantes de distintas ciudades de Petén (Figura 6). Llama la atención sobre una figura sedente de cuerpo completo de un texto jeroglífico, que lleva cargando a manera de mecapal el signo de TUUN, "piedra", del cual surge el "fuego", y agrega que podría ser un indicio de un antiguo dios del fuego que se compartía con el área del México central. 


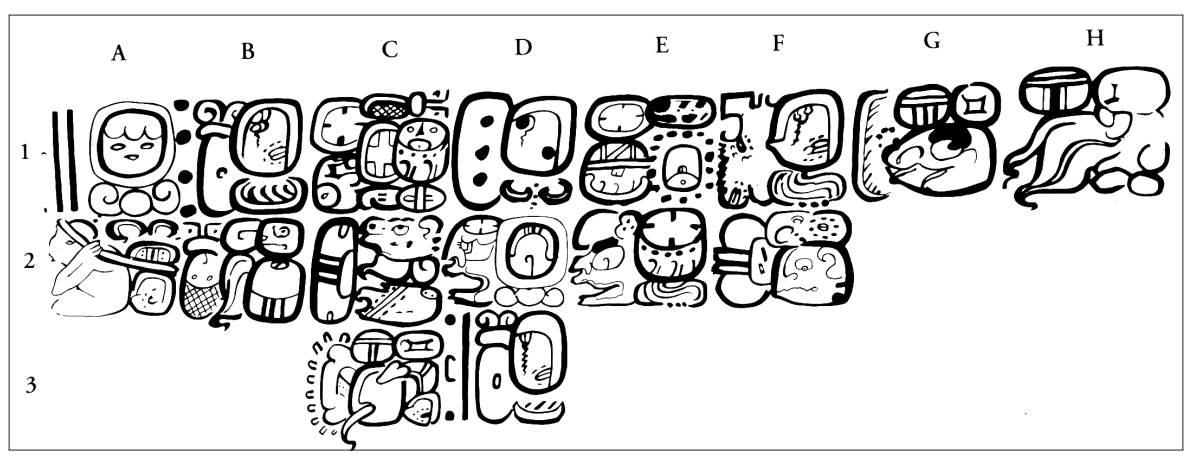

Figura 6. Cueva de Naj Tunich, dibujo 82, A2. (MacLeod y Stone, 1995:179).

Cabe advertir que los mayas al parecer carecían de la imagen de un antiguo dios anciano portando el clásico mecapal como en otras regiones mesoamericanas; sin embargo, varias deidades que figuran en los textos aquí citados se vinculan con el fuego, desde luego Pawaaj Sahb'iin, un dios viejo de los tiempos creacionales, quien entre sus múltiples funciones puede poseer el fuego, y ya Grube (2000:102) hizo notar que este dios se vinculó cuando el fuego se encendía barrenándolo. Por otro lado está GI, a quien en Palenque se le llama "Dios del fuego nuevo"; otra deidad, pero no anciana, que hasta este momento figura en los rituales citados es Yax Xib' Chaahk, ${ }^{31}$ que puede incendiar el cielo y se vincula con la forma til, "quemar" (Grube, 2000: 102). Con toda seguridad cuando avance la investigación surgirán más deidades que se relacionen con este elemento, como el Dios Jaguar del Inframundo.

Sheseña $(2005: 103 ; 2015: 133)$ lee el jeroglífico del hombre que carga un mecapal como kuch' k'ahk', "traer fuego" o tomar "asiento”. Y a esta ceremonia, efectuada el 27 de agosto de $744^{32}$ d.C., acuden dos gobernantes, uno de ellos el de Caracol, ciudad ubicada en el oeste de Belice, donde el Gobernante VIII, Tum Yohl K'inich, 33 bajo la supervisión o autoridad (ukab'iiy) de un divino señor Chaahk ... To’k' K'uhul, gobernante de Ixkún, en el Petén, Guatemala, lleva a cabo un ritual de "acarreo de fuego" en el 793 d.C., que por las fechas tardías pudo ser de la refundación de su ciudad (Sheseña, 2015: 133; Martin y Grube, 2002: 96-97).

En tanto, Brady y Colas (2005: 159) consideran que el jeroglífico podría ser leído como tok, que significa tanto "fuego" como "invasión”, y se estaría refiriendo más que a un portador de fuego a una "actividad incendiaria contra gente y

31 Esta sinonimia de Chaahk en apariencia no alude a su función como un dios relacionado con el fuego; no obstante, existen otros nombres en los que claramente se vincula al fuego, como K'ahk' We'l Chan Chaahk, "Chaahk come fuego en el cielo", que puede referirse a su relación con el rayo y el fuego celeste (García Barrios, 2008: 367), aunque estos términos no figuran en los textos hasta ahora citados.

32 9.15.13.3.13, 13 Hix 4 Sak.

${ }^{33}$ Este gobernante carece del título de k'uhul, lo que indica una menor jerarquía. 
lugares" o guerra. ${ }^{34}$ Para probarlo, recurren al texto de la Estela 2 de Ixkún [C-3] (Figura 7), que contiene el mismo jeroglífico y relata un conflicto de esta ciudad con Ucanal. ${ }^{35}$ Colas (2000: 85-86) plantea que este hecho, al que se le ha llamado "portador de fuego", se registra tres veces, y que lo que indica es una "actividad incendiaria contra gente y lugares" o "guerra", pues se registra el verbo PUL-lu, pul [B11], que corresponde a quemar en una acción de guerra y que el objeto a quemar era el Jeroglífico Emblema de Ixkún [A12]. En la Estela 2 se relata una "acción de quema", tok, que fue llevada a cabo por Ucanal, en febrero del 789 d.C. ${ }^{36}$ en contra de Ixkún, y esta ciudad lanzó una invasión la misma noche, a su vez se menciona que se decapitó a un individuo, seguramente de Ucanal. Por lo tanto, si bien hay evidencia para referirse a la destrucción de las cuevas, y, siguiendo a Sheseña (2014: 70), ésta se acompañaba por un complejo ritual de actividades que se reconocían dentro del contexto de una nueva edificación, estaríamos refiriéndonos a rituales de terminación que incluyen el daño deliberado por fuego para una nueva fundación (Brady y Colas, 2005: 59-60; Colas, 2000: 88-89).

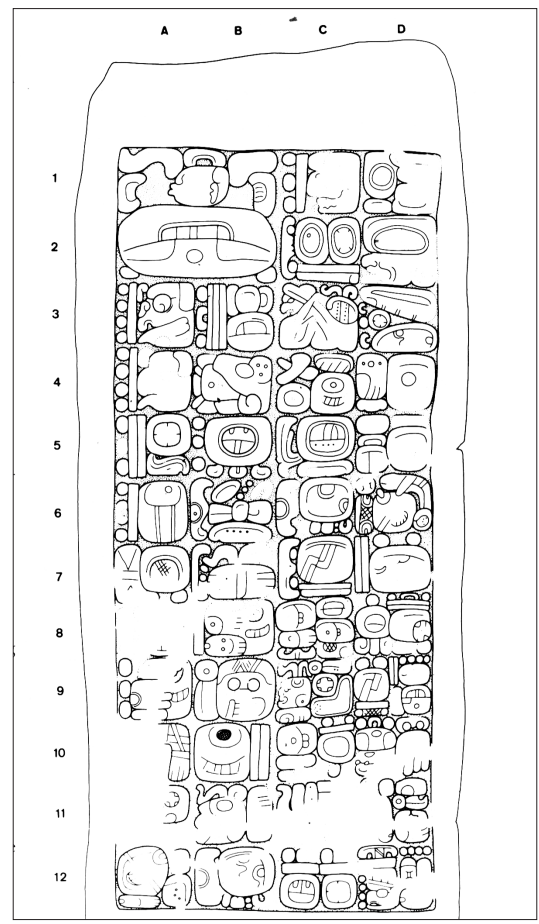

Figura 7. Estela 2 de Ixkun, C3 (Graham, 1980: 141, tomada de Colas, 2000: 89).

\footnotetext{
34 9.15.13.3.14.

35 El conflicto tiene la fecha registrada 9.7.9.9.13. Tanto Ixkún como Ucanal se localizan en el departamento del Petén, en el valle del río Mopán.

36 9.17.9.3.4, 12 Ix 2 Wo.
} 
Sheseña (2014: 70) se refiere a un conflicto similar entre Pe'tun y Sak Tz'i' ${ }^{37}$ en 741 d.C., ${ }^{38}$ por la cueva K'ab Chan Te', "propiedad" de esta última comunidad; considera que las cuevas de los enemigos, por su gran carga simbólica, podrían ser utilizadas por poblaciones rivales para perpetrar ritos fundacionales que incluían el acarreo de fuego y que a través de éstos le quitaban a sus enemigos el derecho sobre sus territorios, lo que responde a la filiación entre la cueva y un asentamiento humano. Por supuesto que este tipo de invasiones provocaría una guerra.

En la tradición del Centro de México analizada por Olivier (2010a: 297-299), en diferentes códices (Códice Azcatitlan: 5; Códice Vaticano A: 66v; Historia Tolteca Chichimeca: 16r; Mapa de Cuauhtinchan 2: A45, A46, A48) se enciende un Fuego Nuevo al salir de las siete cuevas de Chicomoztoc, señalando que podría indicar entre sus múltiples simbolismos el inicio de una nueva temporalidad después del nacimiento de los pueblos o el paso por un lugar mítico.

\section{El fuego se introduce}

Ya hemos visto el encendido de fuego y algunas de sus funciones, pero, una vez que se encendía, ¿con qué otros propósitos se utilizaba? Los templos y edificios sagrados constituyen la habitación de los dioses sobre la tierra, el lugar de su presencia; se sitúan en un centro del mundo imaginario, el espacio nace y se resume en ellos, de ahí la relevancia de su orientación; en general, estas estructuras son un reflejo del mundo divino, son a la vez imágenes microcósmicas y es preciso consagrarlas con algún ritual para que se puedan habitar. También son una expresión de la montaña sagrada, replican su forma natural y su esencia conceptual, porque los dioses viven en ellas. Los templos mayas median las relaciones entre lo sagrado y lo humano, por ello con sus altares sirven como un foco para el ritual.

De ahí que para activarlos era necesario que se introdujera el fuego creador para que lo sagrado invadiera un espacio antes profano, lo purificara y preparara para que los dioses pudieran residir en la tierra. El acontecimiento ha sido leído por Stuart (1998: 384-388, figs. 1 y 8) como "el fuego entra”, och-k'ahk' (Figura 8), que presenta diversas variantes y era una ceremonia para inaugurar diversos recintos arquitectónicos; por ejemplo, se agregaba naah con el sentido de "casa", och-k'ahk' naah, aunque debe entenderse como otoot, "hogar", "la

${ }^{37}$ Estas ciudades se sitúan en la región del Usumacinta y el texto que analiza Sheseña (2014: 6270) es el de Denver-Brussels. Sak Tz'i', señala, fue una pequeña unidad política que ejerció cierto poder en el área entre Piedras Negras y Bonampak. Fue vencido por Piedras Negras y esto desencadena una serie de batallas, entre ellas contra la ciudad de Pe'tun, vasalla de Piedras Negras. El arqueólogo Luis Alberto Martos piensa que Sak Tz'i' es el sitio de Plan de Ayutla (comunicación personal de Sara García Juárez, 2019).

38 9.15.9.9.0. 
mansión familiar" y no como la estructura naah. Y esta morada, al tener valencias femeninas, indica protección, conservación, es una imagen del seno materno, un espacio receptivo, por ello cuando ese fuego, la llama, el elemento masculino, penetra a un edificio o a la nueva residencia de algún dios, le otorga calor, vida, lo fertiliza, significa la conjunción del fuego y su receptáculo; es como un acto de penetración, una nueva procreación, que ratifica un volver al tiempo cosmogónico para recrear ese momento. El edificio con ello se sacraliza, adquiere una fuerza divina y así es posible inaugurarlo.

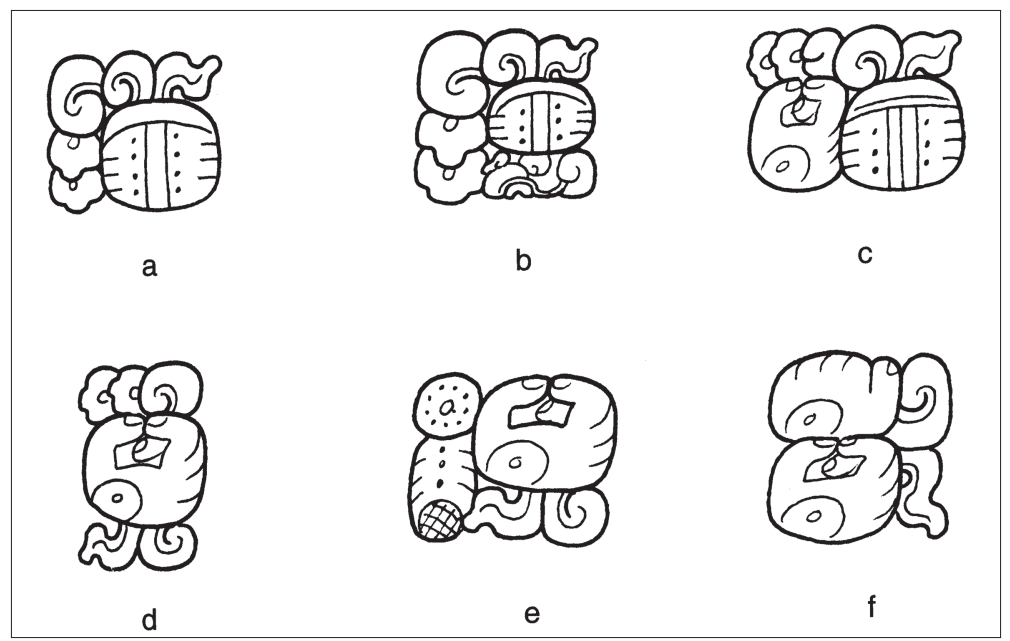

Figura 8. Formas alternativas del jeroglífico och k'ahk', "el fuego entra" (Stuart, 1998: fig. 8).

De Yaxchilán se tienen varios ejemplos, como "la entrada de fuego" que se inscribe en el Dintel 56 [H1-H2] (Graham y Von Euw, 1977: 121, según Stuart, 1998: fig. 7), que inauguró el Edificio 11 construido para la joven esposa de Itzamnaaj B'alam II (681-742 d.C.) en el 738 d. C, ${ }^{39}$ de nombre Ix Sak B'iyaan (Martin y Grube: 2002: 126), ${ }^{40}$ inscripción interesante porque nos indica que no nada más se celebraba este ritual en templos o habitaciones de los gobernantes, sino también en la que posiblemente fue de una de las esposas preferidas.

39 9.15.10.19.01, 7 Imix 13 [14] Sip. Corregido por MINC

${ }^{40}$ De acuerdo con Stuart el texto se refiere a la dedicación de un edificio. La serie inicial empieza con el texto 9.15.6.19.1 $7 \mathrm{Imix} 19 \mathrm{Sip}$, lo cual, de acuerdo con el autor, es un error que atañe a la substracción de 6 de la posición del winal. 
O bien el Dintel $31^{41}$ en el que se dedica la Estructura 10 en el 764 d.C., ${ }^{42}$ que lleva a cabo su hijo, Yaxuun Brahlam (752-768 d.C.) (Martin y Grube, 2002: 128) y que señala "...el fuego se dedica al dios K'inich Itzamnaaj...su santo nombre" (Tate, 1992: 163-165, 777, fig. 57), dato invaluable pues se cita al dios solar y al creador celeste como una unidad y además como dueño de la ofrenda del fuego, quizá en este caso se refiera al fuego solar. De acuerdo con el dintel más tardío de Yaxchilán, el 10 [E1-F1] (Figura 9), el último gobernante de Yaxchilán, K'inich Tatb'u Jol III efectúa un encendido ígneo el 5 de abril del 808 d.C.43 y con ello inaugura el pequeño Templo 3 (García Juárez, 2016, I: 402). Esta expresión difiere de la anterior, pues se emplea la forma ochi k'ahk' tu wahyib'il, que se refiere al "dormitorio", es decir, el repositorio para las imágenes sagradas (Stuart, 1998: 397), el lugar donde descansan, lo cual no deja de ser sugestivo, pues los dioses igual que los humanos, necesitan reponer sus fuerzas, su energía, durmiendo, una de las razones principales de las ofrendas.

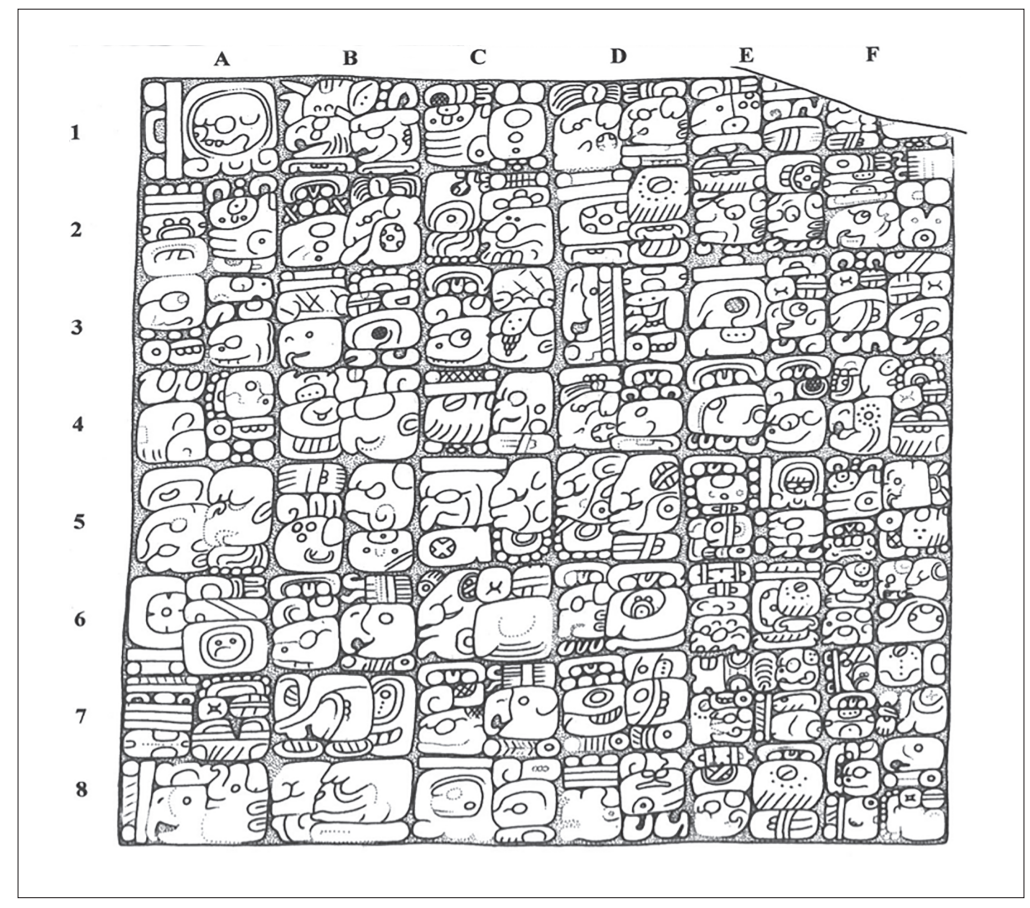

Figura 9. Dintel 10 de Yaxchilán, lado frontal, E1-F1, ochi k'ahk' tu wahyib'il, "la casa del dios" (Dibujo de Ian Graham, tomado de Graham y von Euw, 1977: 3, lámina 31, según Stuart, 1998: 397).

${ }^{41}$ Stuart (1988: 387) aclara, como ya se citó, que en los Dinteles 29 y 30 existe una narrativa que termina en el Dintel 31. Véase nota 15.

42 9.16.13.0.0, 2 Ajaw 8 Woh.

${ }^{43}$ El Dintel 10 tiene tres fechas, la última es 9.18.17.13.14, 9 Hix 2 Tzek, 9 de abril de 808 d.C. Alrededor de ésta última fue capturado K’inich Yat Ahk II de Piedras Negras (García Juárez, 2016: 402). 
En Palenque, Stuart (2010: 24) y Bernal (2006: 90-91, 95-101) han leído diversas dedicaciones de edificios con el ritual och-k'ahk'. Entre ellas, en el Templo XIX, el 10 de enero de 734 d.C., donde se consagra a la deidad GI, "el Dios del Fuego Nuevo"; ${ }^{44}$ en el Edificio XX-A, designado "Las tres Cavidades Terrestres de los Cráneos y los Huesos”, dedicado a GII, Unen-K'awiil, una deidad capaz de incendiar el fuego celeste, y en el Templo XXI o “la Casa de la Lechuza O' -Serpiente del Sol”, a GIII, el Jaguar del inframundo; en estos dos el "fuego entra" el 9 de junio de 736 d.C. ${ }^{45}$ Varios estudiosos (Houston, Stuart y Taube, 2006: 85, 170; Stuart, 1998: 408; Taube, 1992: 54) han considerado precisamente al Jaguar del Inframundo como el dios del fuego entre los mayas, pero considero que aún faltan investigaciones para afirmarlo y sobre todo para identificarlo con GIII, aunque es interesante que los tres dioses de la tríada palencana se relacionen con el fuego.

\section{El fuego entra a su tumba}

Stuart (1998: 373-375, 396-399) reporta otra ceremonia vinculada con el fuego, se trata de ochi k'ahk' tu mukil (Figura 10), "el fuego entra a su tumba”, actividad llevada cabo por el gobernante en turno años después de la muerte de su antecesor o del fundador de la dinastía. Podríamos imaginarnos que la ceremonia ocurriría durante la noche, en la oscuridad, y que consistía, de acuerdo con García y Velásquez (2018: 202-204), en separar el cráneo y los huesos del antiguo gobernante y prender fuegos en el interior de la tumba. Según ambos autores, los participantes podrían personificar al dios del inframundo, divinidad que se ha considerado como un dios del fuego. Señalaré algunos ejemplos de ello en orden cronológico.

En Copán, sitio ubicado en el valle del Motagua, Sharer y Traxler (2005: 154155) muestran algunos modelos de este ritual para el Clásico Temprano, aunque no en los textos glíficos sino en la evidencia arqueológica. Se trata de las tumbas del Edificio 16, Hunal (circa 437 d.C.), que contenían los restos del Gobernante 1, K'inich Yax K'uk' Mo', fundador de la dinastía copaneca, y Margarita (circa 460 d.C.), donde se encontraba su esposa. Se hallaron restos de cinabrio o sulfato de mercurio, elemento diagnóstico que se produce en los rituales de reingreso con fuego; además, en el Templo Margarita, había una vasija que se empleó para este ritual, huesos y un guajolote quemado. En los rituales de post-enterramiento, en la tumba de Hunal, los huesos fueron embadurnados de cinabrio con posterioridad a que el cuerpo se esqueletizara, lo que tendría la misma intención que el fuego, ya que éste por su color recuerda a la sangre y, por ende, a la vida (Sharer y Traxler, 2005: 154-155; Agurcia, 2005: figura 1). Tales datos sugieren que no sólo era importante la entrada de fuego sino la quema de ofrendas y nos

44 9.15.2.7.12, 5 Eb' 15 K'ayab'.

45 9.15.4.15.8, 2 B'en 1 Yaxk'in. 
dan una idea de lo elaborada que debió ser esta ceremonia, el volver a tener contacto con los antepasados y ofrecerles alimento, pues los gobernantes ya fallecidos se habían divinizado con su muerte, de donde deriva la justificación del poder de los gobernantes en turno. El Templo de Rosalila dedicado al Sol tenía los muros interiores cubiertos de hollín y siete incensarios con restos de carbón que rememoran los antiguos rituales (Taube, 2004: 277). Recientemente Seiichi Nakamura (2016) descubrió restos de fuego en las tumbas excavadas en la Estructura 9L-105 fechadas entre el 500 d.C. y 550 d.C., y opina que pertenecieron a la dinastía fundadora copaneca.

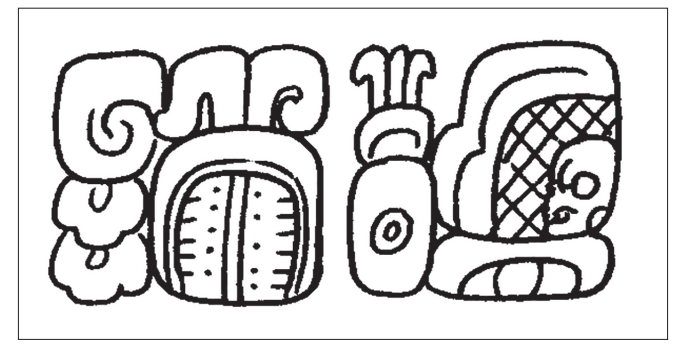

Figura 10. Frase de dedicación del Monumento 175 de Toniná, Ochi k'ahk' tu mukil (Stuart, 1988: fig. 13).

Retomando los datos que proporcionan los epigrafistas en las tierras altas, uno de los ejemplos más tempranos es el fragmento de un tablero saqueado de origen desconocido (Monumento 139), que hoy se exhibe en el museo de Emiliano Zapata, ${ }^{46}$ en el que se describe la entrada con fuego a la tumba de Chak B'olon Chaahk, gobernante de Toniná, que pudo ocurrir en el 589 d.C. (Martin y Grube, 2002: 178-179; Pérez Suárez, 2015: 159). Por su parte, Bernal localiza en la Estela de Tzendales $^{47}$ una ceremonia funeraria al anochecer del 11 de abril de 691 d.C. ${ }^{48}$ para recordar a un gobernante que, según Stuart, se llamó K'ahk' Witz' K'awiil. El texto registra "entró el fuego a Yej Te' Naah ('la Casa de la Lanza Afilada'), que es el nombre de la tumba, (en) Ju'n Tz'i'nal, del Gobernante de 1 K'atun, K'ahk' Witz' K'awiil, Gobernante de .... (la localidad de Tzendales)" (Bernal, 2014b, figura 8 [C-D]).

En un fragmento muy deteriorado de un tablero de Pomoná, sitio estratégico ubicado en las planicies costeras de Tabasco, en las tierras bajas noroccidentales, el gobernante Kuuch K'in B'ahlam realiza una visita con fuego en la tumba de K'inich Ho’ B’ahlam posiblemente el 16 de marzo de 696 d.C. ${ }^{49}$ (Pérez Suárez, 2016).

\footnotetext{
${ }^{46}$ El nombre oficial del museo es "Museo de la Ciudad Arq. Ventura Marín Azcuaga", Ayuntamiento de Emiliano Zapata, Tabasco.

47 De acuerdo con el autor, su localidad es incierta, se encuentra en la zona de Ocosingo, cerca de Toniná.

48 9.12.19.1.11, 7 Imix 13 [14] Sip.

49 9.13.5.0.19, 11 Kawak 7 Woh.
} 
Otro ejemplo, de la ya citada belicosa ciudad de Toniná, es el que proviene del gran altar circular conmemorativo dominado por el signo del día $5 \mathrm{~Eb}$, el Monumento 161; en éste el Gobernante 5, K'inich Ich'aak Chapaat (723-739 d.C.), el 20 de junio de 730 d.C. ${ }^{50}$ conduce "el ingreso con fuego a la tumba", ochi k'ahk' tu muk, de uno de sus antecesores, el Gobernante 3, K'inich B'aaknal Chaahk (688-704 d.C.), quien había ascendido al trono 42 años antes. Por otro lado, resulta relevante que en Toniná se encontró una tumba con urnas conteniendo huesos quemados y molidos, que quizá son un vestigio material de este ritual (Martin y Grube, 2002: 186-187; Pérez Suárez, 2015: 159). Supongo que el moler los huesos y no sólo quemarlos le dio un sentido particular al rito, no solo de purificación, sino también de lograr una dilución mayor, para que fueran más fáciles de asimilarse a esas "otras realidades" que constantemente intervenían en la vida diaria del hombre.

Proveniente también de Toniná, en el Monumento 175, el Gobernante 8, K'inich?-? Chapaat (766-? d.C.), "el de los muchos cautivos", efectúa, el 31 de octubre de 799 d.C. ${ }^{51}$ una visita con fuego al fundador de la dinastía K'inich Hix Chapaat (606-665? d.C.), ${ }^{52}$ quien había fallecido alrededor de 130 años antes (Martin y Grube, 2002: 178-179, 188; Bernal, 2015: 162). ${ }^{53}$ Es sugerente que la narración, de acuerdo con Martin y Grube, se traslada diez años después a la captura del señor de Pomoy $^{54}$ (Bernal y Laló, 2006: 10), que fue en la que K'inich Ix Chapaat, mostraba sus mayores logros militares, por lo tanto la ceremonia del fuego no sólo implica honrar al fundador que seguramente había sido deificado, sino también recordar su gran conquista.

En el Tablero 5 (C1-D2) de la ciudad Ceibal, asentada a la orilla izquierda del río de la Pasión, el tema central de la narrativa es que el k'uhul ajaw Yich'aak B'ahlam realiza el 30 de octubre de 747 d.C.55 una acción sagrada, ochi k'ahk' tu muknal, "introduce fuego sagrado en la tumba" de un antepasado, el señor K'an Mo' B’ahlam, el Sagrado Señor de Ceibal, de quien se desconoce cuándo gobernó, pero existen sugerencias de que fue 300 años antes. El ritual fue supervisado por K'awiil Chan K'inich de Dos Pilas, relevante ciudad ubicada en la región del Petexbatún (Stuart, 1998: 398, fig. 15; Vega, 2009: 185, fig. 46b; Somohano y Jaramillo, 2015: 730-731), lo que indica una vez más la relevancia política del ritual, ya que Ceibal se encontraba bajo el control de esta ciudad. Llama la atención que el gobernante que ostenta el dominio asiste a la ceremonia de la ciudad subordi-

50 9.14.18.14.14, 5 Eb' 10 Yaxk'in.

51 9.18.9.3.13, 3 Manik' 0 Muwaan.

52 K'inich Ix Chapat nace en 606.

53 En el monumento también se menciona “que diez años antes, en 2 Muluk 12 Ch'e'n, 13 de julio de 789 d.C., el Gobernante 8 capturó a Aj Chan Chih", un noble originario de un sitio llamado Pomoy, que quizá se identifique con el sitio arqueológico El Palma, asentamiento situado cerca de la población de Zamora-Pico de Oro, en marqués de Comillas, Chiapas. La escena muestra a este prisionero, amarrado y llevándose una mano a los labios, gesto corporal que indica temor (Bernal, 2015: 162).

54 Probablemente El Palma, Chiapas (Bernal y Laló, 2006: 10).

55 9.15.16.7.17, 6 K'aban 10 Kankin. 
nada, y al llevarse a cabo reafirmaba su poder, obtenía la protección o tal vez la supremacía sobre uno de los ancestros de Ceibal.

Para Piedras Negras, García Juárez (2016: 124, 142-148) proporciona una rica cantidad de datos y analiza otra ceremonia funeraria que implica también una penetración del fuego a la tumba de los antepasados con peculiaridades diferentes. En esta ocasión se lleva a cabo a través del encendido de una cuerda. Propone para tal rito la lectura puluuy u tz'itil, "objeto alargado", "se quemó la cuerda flameante", y encuentra el mismo evento en las Estelas 1, 9, 23 y 40. La autora proporciona varios ejemplos que citaré cronológicamente.

El más temprano es el de la Estela 1, lado derecho [J9-K16] (Figura 11) (García Juárez, 2016, I: 124, 148-149, 392-395; II: 542, fig. 2.27) en la que se cita que K'inich Yo'nal Ahk II (664-729 d.C.) asciende al trono a los 23 años, en 687 d.C., y cuando casi cumplía su primer k'atun en el poder, el 10 de agosto de 706 d.C., ${ }^{56}$ condujo un rito puluy utz'itil (Martin y Grube, 2002: 146), quema el tzit (la cuerda de) para conmemorar el primer k'atun del entierro de su padre, Itzam K'an Ahk I (639-686 d.C.). Con este acto ritual y político seguramente reafirmaba su propio poder a los 20 años de su ascenso al trono. La Estela 9 (García Juárez, 2016, I: 150-151; II: 535, fig. 2.21 y 539, fig. 2.25) la manda labrar su descendiente, el gobernante Itzam K'an Ahk II (701-757 d.C.), en ésta se registra su nacimiento, su ascenso al trono a los 28 años y conmemora su quinto año en el poder, así como la atadura de piedra o erección de la estela el 22 de julio de 736 d.C., ${ }^{57}$ cinco días después ${ }^{58}$ se efectúa el pul(uu)y u tz’itil [C11-C13] . Cumple, al igual que su antecesor, el ritual establecido en este caso en el séptimo aniversario-tuun del entierro de K'inich Yo'nal Ahk II y finaliza el séptimo tuun en el señorío (García Juárez, 2016: I, 396; II: 539, fig. 2.25 [D11-13C]). En la Estela 23 le corresponde a Ha' K'in Xook ${ }^{59}$ (758-781 d.C.), descendiente de Itzam K'an Ahk II, “el de la tumba sagrada”, llevar a cabo el mismo ritual funerario, pul|uuly u tz'itil, el 22 de septiembre de 770 d.C., en el 13ำ aniversario del entierro de su antecesor, cuando el joven gobernante tenía tres años de su ascenso al trono (García Juárez, 2016, I: 393- 415; II: 679, fig. 4.30 [I8-J8]; 680, fig. 4.31 [K1-L1]).

Dejo aparte el ritual funerario que se caracteriza en la Estela 40 (Figura 12), porque resulta el más concluyente y reafirma las anteriores lecturas de García Juárez (2016, I: 158-168; II: 564). En la imagen se lleva a cabo el rito donde se penetra a una tumba con una cuerda encendida, aunque no se puede saber si estaba mencionado ese ritual en el texto porque se encuentra muy erosionado. En este caso, se trata del mismo Itzam K'an Ahk II, Sagrado Gobernante de Yo(kib'), quien abre la tumba y establece un contacto con un antepasado, tal vez K’inich Yo'nal Ahk II, su padre. El regente, señala la autora, conmemora el últi-

56 9.13.14.11.1, 4 Imix 19 Ch'en.

57 9.15.5.0.0, 10 Ajaw 8 Ch'en.

58 9.15.5.0.5, 2 Chikchan 13 Ch'en.

${ }^{59}$ La fecha de nacimiento de Ha' K’in Xook no se conoce, García Juárez (2016: 399-401, 678) la reconstruye tentativamente en 9.16.07.07.13, 10 B'en 11 Sak, 29 de agosto de 758 d.C. 


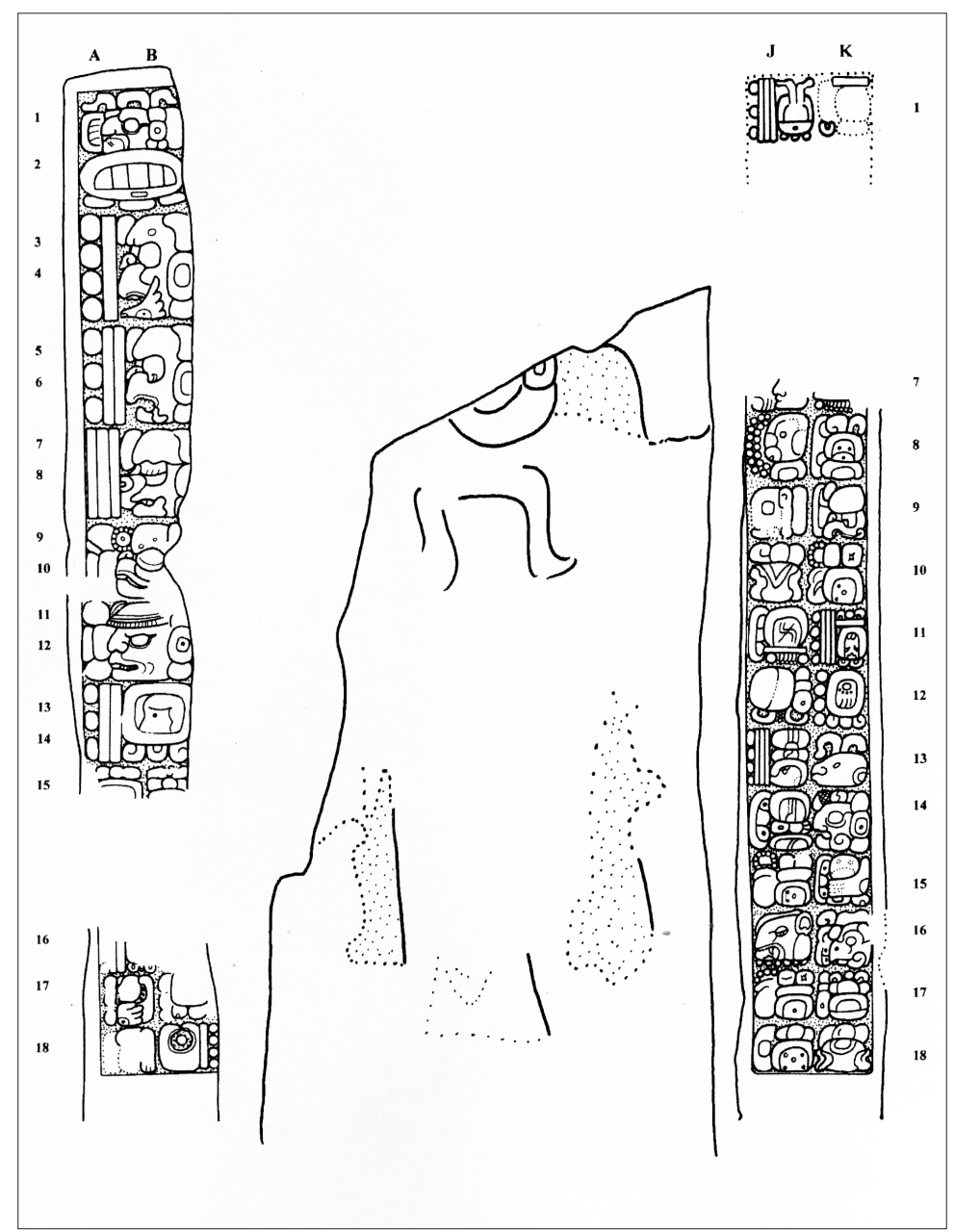

Figura 11. Estela 1 [J9-K16] de Piedras Negras (García Juárez, 2016, II: 542, fig. 2.27).

mo periodo de cinco tunes el 31 de mayo de 746 d.C.;60 se muestra arrodillado sobre una cavidad con las marcas de kab', "tierra", y porta en su mano izquierda una bolsa de incienso, y con la derecha lo asperja (chok (ch'alaj) hacia la cavidad inframundana llamada "la cavidad subterránea de las nueve llegadas", la casa de la "muerte blanca". Se menciona a su vez el asperjamiento de incienso de la familia Winikhaab'?, “de la familia de los 16 Señores”, personajes del mismo linaje de Yokib', por lo que supongo que a través del ritual se convierte en un ancestro deificado y se une a los 16 Señores.

60 9.15.15.0.0, 9 Ajaw 18 Xul. 


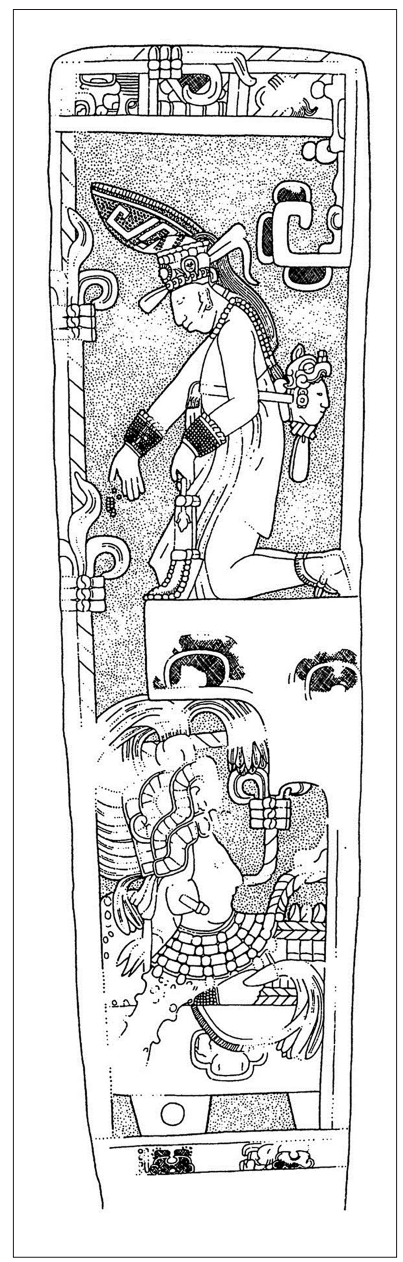

Figura 12. Estela 40 de Piedras Negras, parte frontal (Dibujo de John Montgomery (JM05530) (C 2000. Montgomery Drawing Collection, http://www.famsi.org/research/montgomery).

Al lado derecho superior de Itzam K'an Ahk II se aprecia al Monstruo Sip o la "Serpiente de Nariz Cuadrada", que, de acuerdo con Stuart (2010: 22-23), constituye uno de los rasgos diagnósticos del dios solar (Kinich), por lo tanto es una fuerza radiante la que penetra (Stone y Zender, 2011: 99), ${ }^{61}$ que se transforma en una larga cuerda con tres nudos con motivos flamígeros, cruza los tres niveles cósmicos y termina en la nariz del personaje ya fallecido, como si fuera una forma de aliento que le otorga vida. A través de la cuerda, la flama entra a la tumba (García Juárez, 2016: 158-168, 395-396 fig. 2.39; Houston et al, 2003: 113).

${ }^{61}$ Según Stone y Zender (2011: 99) personifica a una fuerza o una energía radiante que se expele a través de la boca, la nariz o del interior de una flor y se dispersa a través del universo. 
A diferencia de los rituales de entrada del fuego a la tumba que vimos con anterioridad, los de Piedras Negras tienen la peculiaridad de que no sólo se pueden llevar a cabo de padre a hijo, sino que el fuego irrumpe a través de una cuerda flamígera y en periodos de 7, 13 o 20 años, números que poseen una fuerte carga simbólica. Los otros rituales citados de Ceibal, Toniná y quizá de Pomoná, no se efectúan para el ascendiente directo, sino para los ancestros del linaje, mostrando con ello una similitud, pero a la vez una diferencia. No obstante, de una u otra forma permiten la comunicación con los ya fallecidos. Parece también factible que las ciudades que mostraron más poder es donde se encuentra el registro de mayor número de entradas a las tumbas de los antepasados.

Desde mi punto de vista, la tumba es, por lo tanto, no sólo un lugar de la muerte, sino también uno de los depósitos de la vida, en donde se afirma la perennidad de la existencia a través de las transformaciones producidas por el fuego; es también la nueva casa para la eternidad, ya que resguarda con un signo material el cuerpo y alma del que falleció. Y contiene además valencias femeninas, es la madre tierra que envuelve, protege; es el hogar de los que han fallecido y un lugar de metamorfosis en donde algunas de las entidades anímicas continúan existiendo y manteniendo su comunicación con la vida terrenal. Los gobernantes emulan la muerte del Dios del Maíz y esperan volver a renacer, igual que la semilla reverdece después del proceso de siembra que incluye la roza, que enriquece la tierra, como lo muestra el Vaso de Berlín, en donde el gobernante está ataviado como dicha deidad; la "entrada del fuego a la tumba" sería equivalente al proceso agrícola porque los campos necesitan la ceniza para la nueva mazorca, el gobernante renacido continuará así sustentando a su pueblo y acentúa el poder transformador del fuego.

Pero los rituales son polivalentes, y cuando el fuego penetraba en la tumba debió formar parte también de un proceso de deificación de los antepasados a través de su poder purificador y transformador, y al mismo tiempo el gobernante que lo realizaba se revaluaba a sí mismo y legitimaba su poder. Se invitaba al difunto a testificar dicho poder y con ello se lograba mantener el control político centralizado y a reconocer la autoridad de los gobernantes a través de sus predecesores. De ahí que se desarrollara un verdadero culto a los ancestros, pues eran quienes testificaban la transmisión del poder.

\section{Comentarios finales}

El fuego desde esta perspectiva es una potencia sagrada y uno de los elementos creadores del cosmos, así como responsable de su revitalización y continuidad. De ahí su intensa relación con el tiempo y su empleo como marcador para establecer una nueva temporalidad. Porque la creación se llevó a cabo a partir de una transmutación del fuego y dio como resultado el mundo donde habita el hombre (Limón, 2001: 16). Cada vez que se encendía ritualmente, se producía un fuego 
nuevo y con este elemento no sólo se renovaba el tiempo, sino también se "invadían" diferentes espacios, ya sea edificaciones o cuevas, para consagrarlos, purificarlos, dotarlos de una existencia; así, se reactualizaba el momento prístino de la creación y con ello se convertían estos recintos en repositorios de los dioses. De hecho, podemos decir que en el instante en el que el fuego penetraba a un edificio, era cuando realmente se fundaba, adquiría una fuerza sagrada, y también en los casos en los que se volvía a inaugurar el espacio sufría una transformación; era a su vez un proceso por el que los seres sobrenaturales se apropiaban de ellos y permitían que los hombres los habitaran.

Por otro lado, era fundamental en uno de los procesos liminares que el gobernante realizaba durante su ceremonia de acceso al poder, indispensable para lograr una articulación entre un tiempo pasado y uno nuevo y marcaba la transición de un estado de vida a otro superior. El fuego fue asimismo una ofrenda para los dioses, no sólo como elemento, sino porque al ser el gran transformador, al quemar otras dádivas, como sangre o copal, las convertía en alimento ligero para las divinidades. No podemos dejar de mencionar que políticamente también simbolizaba preeminencia, superioridad cultural y poder (Limón, 2001: 293), y por ello su uso y sacralización fue tan relevante para la clase gobernante.

El fuego, cuando penetraba en las tumbas, se convertía en un intermediario entre los vivos y los muertos y funcionaba como el principal agente de cambio que permitió a los gobernantes que habían fallecido convertirse en deidades, proteger a sus sucesores y con ello autentificar que sus descendientes tenían el derecho pleno a regir. Además, en Piedras Negras, la ceremonia de la entrada de la cuerda de fuego del hijo a la cámara mortuoria de su antecesor quizá era una forma de separar a los que habían iniciado su viaje por el camino de la muerte y ayudarlos a alcanzar su última morada. Y este componente ígneo, señala López Austin (2012, I: 370), es "el elemento transformador de todo lo existente, el que puede romper la barrera entre el mundo habitado por los hombres y los sitios en los que moran los dioses".

\section{Bibliografía}

Agurcia Fasquelle, Ricardo

2006 “Rosalila: templo del rey Sol en Copán”, Los mayas. Señores de la creación: los orígenes de la realeza sagrada, pp. 72-74, Virginia M. Fields y Dorie ReentsBudet (eds.). México: Consejo Nacional para la Cultura y las Artes, Instituto Nacional de Antropología e Historia.

Bell, Catherine

2009 Ritual. Perspectives and Dimensions. New York: Oxford University Press.

Bernal Romero, Guillermo

2006 El trono de K'innich Ahkal Mo' Nahb': una inscripción glífica del Templo XXI de 
Palenque, tesis de maestría en Estudios Mesoamericanos. México: Universidad Nacional Autónoma de México, Programa de Posgrado en Estudios Mesoamericanos, Facultad de Filosofía y Letras, Instituto de Investigaciones Filológicas.

2009a "Dignatarios cuatripartitas y cultos direccionales en las inscripciones de Palenque, Copán y Quiriguá, Primera parte”, Lakamha', 31: 2-13.

2009b "Dignatarios cuatripartitas y cultos direccionales en las inscripciones de Palenque, Copán y Quiriguá. Segunda Parte”, Lakamha', 32: 2-9.

2011 "El señorío de Palenque durante la era de K'inich Janaahb' Pakal y K’inich Kan B'ahlam (615-702 d.C.)", tesis de doctorado en Estudios Mesoamericanos. México: Universidad Nacional Autónoma de México, Programa de Posgrado en Estudios Mesoamericanos, Facultad de Filosofía y Letras, Instituto de Investigaciones Filológicas.

2014a "El fuego, el taladro y el tlacuache. Ritos de joch k'ahk y otras ceremonias de fuego en el Clásico", Arqueología Mexicana, XXII (128): 66-71.

2014b "Jeroglíficos enigmáticos de la escritura maya. El logograma T514, YEJ, 'filo”" [https://www.academia.edu/12620139/EL_LOGOGRAMA_T514_YEJ_FILO_Jeroglíficos_Enigm\%C3\%A1ticos_de_la_Escritura_Maya_VERSI\%C3\%93N_LARGA_. Consultado el 18 de enero de 2017$]$.

2015 "Mónumento 175 de Toniná Chiapas", no. catálogo 161, p. 162, en Mayas. Revelación de un tiempo sin fin. Mercedes de la Garza (coord.). México: Instituto Nacional de Antropología e Historia.

2016 "El ciclo de 63 días en la cultura maya: descubrimiento de un nuevo factor calendárico", El papel de la arqueoastronomía en el mundo maya: el caso de la Isla de Cozumel, pp. 111-124. México: Organización de las Naciones Unidas para la Educación, la Ciencia y la Cultura (UNESCO).

Bernal Romero Guillermo y Gabriel Laló Jacinto

2006 "Pomoy. Una de las ciudades perdidas de los mayas", Noticias, Arqueología Mexicana, 4 (79): 10.

Boot, Erik

2005 Continuity and Change in Text and Image at Chichén Itzá, Yucatán, México: A Study of the Inscriptions, Iconography, and Architecture at a Late Classic to Early Postclassical Maya Site. Leiden: Research School Centre of Non-Western Studies, Leiden University (CNWS Publications, 135).

Brady, James y Pierre Colas

2005 'Nikte' Mo' Scattered Fire into the Cave of K'ab Chante'. Epigraphic and Archaeological Evidence for Cave Desecration in Ancient Maya Warfare", Stone Houses and Earth Lords. Maya Religion in Cave Context, pp. 149-166, Keith M. Prufer y James E. Brady (eds.). Boulder, Colorado: University Press of Colorado.

Colas, Pierre Robert

2000 “Tok' and Tok: Two Examples of Rebus Writing in Maya Script”, The Sacred and the Profane, Architecture and Identity in the Maya Lowlands, 3rd European Maya Conference, pp. 83-92, Pierre R. Colas, Kai Delvendahl, Marcus Kuhnert 
y Anette Schubart (eds.). Markt Schwaben: Verlag Anton Saurwein (Acta Mesoamericana, 10).

Chinchilla Mazariegos, Oswaldo

2018 "Fire and Sacrifice in Mesoamerican Myths and Rituals", Smoke, Flames, and the Human Body in Mesoamerican Ritual Practice, pp. 29-53, Vera Tiesler y Andrew K. Scherer (eds.). Washington, D.C.: Dumbarton Oaks Research Library and Collection.

Chinchilla Mazariegos, Oswaldo y Oswaldo Gómez

2010 "El nacimiento del sol en Tikal: Interpretación de un entierro en Tikal asociado al conjunto de tipo 'Grupo E' de Mundo Perdido”, XXIII Simposio de Investigaciones Arqueológicas en Guatemala, 2009, pp. 1193-1201, Bárbara Arroyo, Adriana Linares, Lorena Páiz y Ana Lucía Arroyave (eds.). Guatemala: Ministerio de Cultura y Deportes, Instituto de Antropología e Historia y Asociación Tikal.

Chinchilla Mazariegos, Oswaldo, Vera Tiesler, Oswaldo Gómez y T. Douglas Price

2015 "Myth, Ritual, and Human Sacrifice in Early Classic Mesomerica: Interpreting a Cremated Double Burial from Tikal, Guatemala", Cambridge Archaeological Journal, 25: 187-210. DOI: 10.1017/S0959774314000638.

Diccionario maya-español, español-maya

1980 Alfredo Barrera Vásquez (dir.), Juan Ramón Bastarrachea y William Brito (reds.). Mérida: Ediciones Cordemex.

29: $11-15$

Fahsen, Federico, Arthur A. Demarest y Luis Fernando Luin

2003 "Sesenta años de historia en la escalinata jeroglífica de Cancuén", XVI Simposio de Investigaciones Arqueológicas en Guatemala, 2002, pp. 703- 713, J. P. Laporte, B. Arroyo, H. Escobedo y H. Mejía (eds.). Guatemala: Museo Nacional de Arqueología y Etnología, < httpw:/www.asociaciontikal.com.pdf.> [Consultado el 30 de junio de 2016].

García Barrios, Ana

2008 Chaahk, el dios de la lluvia, en el periodo Clásico maya: aspectos religiosos y políticos. Tesis doctoral, Madrid, Universidad Complutense de Madrid.

García Barrios, Ana y Erik Velásquez García

2018 El arte de los reyes mayas, Puebla: Museo Amparo, Programa de Estudios y de Investigación de la Colección del Museo Amparo.

García Campillo, José Ma.

1999 "Implicaciones de un aniversario de doce años túnicos en las inscripciones de Chichén Itzá”, Revista Española de Antropología Americana, 29: 131-157. Chichén M Campillo José M. García Campillo 
García Juárez, Sara Isabel

2016 "La historia de Piedras Negras a través de sus inscripciones jeroglíficas: auge y ocaso del linaje de las Tortugas", tesis de licenciatura en Historia. México: Universidad Nacional Autónoma de México, Facultad de Filosofía y Letras: 2 vols.

2017 "Yokib'Chan Ch'e'en, "El cielo y el pozo de Yokib": Historia sagrada y espacios primordiales de Piedras Negras", ponencia presentada para el Premio Palenque, <https://www.academia.edu/35128255/Yokib_Chan_Cheen_el_ Cielo_y_el_Pozo_de_Yokib_historia_sagrada_y_espacios_primordiales_de _ Piedras_Negras._MENCI\%C3\%93N_HONOR\%C3\%8DFICA_PREMIO_PALENQUE_2017> (Consultada el 20 de noviembre de 2018).

Garza, Mercedes de la, Guillermo Bernal y Martha Cuevas

2012 Palenque-Lakamha' Una presencia inmortal del pasado indígena. México: Fondo de Cultura Económica, El Colegio de México.

Graham, Ian y Eric von Euw

1977 Corpus of Maya Hieroglyphic Inscriptions, vol. 3, num. 1, Yaxchilán. Cambridge: Peabody Museum of Archaeology and Ethnology, Harvard University.

Grube, Nikolai

2000 "Fire Rituals in the Context of Classic Maya Initial Series", The Sacred and the Profane. Architecture and Identity in the Maya Lowlands, 3rd European Maya Conference, pp. 93-110, Pierre R. Colas, Kai Delvendahl, Marcus Kuhnert y Annete Schubart (eds.). Markt Schwaben: Verlag Anton Saurwein (Acta Mesoamericana, 10).

Grube, Nikolai y Ruth J. Krochock

2011 "Reading Between the Lines: Hieroglyphic Texts from Chichén Itzá and its Neighbors", Twin Tollans, Chichén Itzá, Tula, and Epiclassic Mesoamerican World, pp. 157-194, Jeff Karl Kowalski y Cynthia Kristan-Graham (eds.), Washington: Dumbarton Oaks Research Library and Collection, Harvard University Press.

Grube, Nikolai, Alfonso Lacadena y Simon Martin

2003 "Chichén Itzá and its Neighbors", Notebook for the 27h Maya Hieroglyphic Forum at Texas, pt. 2: Chichén Itzá and Ek Balam: Terminal Classic Inscriptions from Yucatan, pp. 1-84. Austin: University of Texas, Center for the History of Ancient American Art and Civilization, Department of Art and Art History.

Houston, Stephen D., David Stuart y Karl A. Taube

2006 The Memory of Bones: Body, Being, and Experience among the Classic Maya. Austin: University of Texas Press.

Houston, Stephen D., Andrew Scherer, Héctor Escobedo, Mark Child y James Fitzsimmons 2003 "Classic Maya Death at Piedras", Antropología de la eternidad: la muerte en la cultura maya, pp. 113-144, Andrés Ciudad Ruiz, Mario H. Ruz y María Josefa Iglesias (eds.). Madrid / México: Sociedad Española de Estudios Mayas, Universidad Nacional Autónoma de México, Instituto de Investigaciones Filológicas, Centro de Estudios Mayas (Publicaciones de la Sociedad Española de Estudios Mayas, 7). 
Inomata, Takeshi y Daniela Triadan

2015 "Middle Preclassic Caches from Ceibal, Guatemala”, Maya Archaeology, 3: 53-91.

Jackson, Sarah E.

2013 Politics of the Maya Court. Hierarchy and Change in the Late Classic Period, Norman: University of Oklahoma Press.

Lacadena García-Gallo, Alfonso,

2003 "El corpus glífico de Ek’ Balam, Yucatán, México", <http://www.famsi.org/ reports/01057es/index.html> [Consultado el 3 de marzo de 2016].

2004 "Tiempo histórico y tiempo mítico entre los mayas del periodo Clásico", Disparidades. Revista de Antropología, 59 (1): 83-106. DOI: 10.3989/rdtp.2004. v59.i1.142.

Limón Olvera, Silvia

2001 El fuego sagrado: simbolismo y ritualidad entre los nahuas. México: Instituto Nacional de Antropología e Historia, Universidad Nacional Autónoma de México.

López Austin, Alfredo

1996 Los mitos del tlacuache. Caminos de la mitología mesoamericana. México: Universidad Nacional Autónoma de México, Instituto de investigaciones Antropológicas.

2012 Cuerpo humano e ideología. Las concepciones de los antiguos nahuas, I. México: Universidad Nacional Autónoma de México, Instituto de Investigaciones Antropológicas.

MacLeod, Barbara y Andrea Stone

1995 "The Hieroglyphic Inscriptions of Naj Tunich", Images from the Underworld. Naj Tunich and the Tradition of Maya Cave Painting, pp. 155-184, Andrea Stone (ed.). Austin: Universidad of Texas Press.

Martin, Simon

2015 "The Old Man of the Maya Universe: A Unitary Dimension To Ancient Maya Religion, Maya Archaeology, 3: 186-227.

Martin, Simon y Nikolai Grube

2002 Crónica de los reyes y reinas mayas. La primera historia de las dinastías mayas. México: Editorial Planeta.

Nakamura, Seiichi

2016 "Descubren importantes tumbas mayas e indicios de ritos con fuego en Copán”, National Geographic España. Octubre, <https://www.nationalgeographic.com.es/historia/actualidad/descubren-importantes-tumbas-mayas-indicios-ritos-con-fuego-copan_10743/1> [consultado el 18 de agosto de 2017].

Olivier, Guilhem

2010a "Bultos sagrados, flechas y Fuego Nuevo. Fundación y poder en el Mapa de Cuauhtinchan número 2", Cueva, ciudad y nido de águila: una travesía por el 
Mapa de Cuauhtinchan número 2, pp. 281-313, David Carrasco y Scott Sessions (eds.). Alburquerque: University of New Mexico Press.

2010b "Los bultos sagrados. Identidad fundadora de los pueblos mesoamericanos", Arqueología Mexicana, XVIII (106): 53-59.

Pérez Suárez, Tomás

2015 "Monumento 161 de Toniná, Chiapas", no. Catálogo 155, Mayas. Revelación de un tiempo sin fin, pp. 159, Mercedes de la Garza (coord.). México: Instituto Nacional de Antropología e Historia.

2016 "Pomoná, Tabasco. Una revisión histórica del sitio y sus inscripciones", ponencia presentada en Los mayas de ayer y hoy, IV Mesa Redonda del Mayab, 14-22 de octubre de 2016, Mérida, Yucatán.

Pitts, Mark

2011 A Brief History of Piedras Negras as Told by the Ancient Maya. History revealed in Maya Glyphs, The Aid and Education Project, Inc., < http://www.famsi.org/ research/pitts/pitts_piedras_negras_history.pdf $>$ [Consultado el 16 de mayo de 2016].

Sharer, Robert J. y Loa P. Taxler

2005 "Las tumbas reales más tempranas de Copán: muerte y renacimiento en un reino maya clásico", Los mayas. Señores de la creación: los orígenes de la realeza sagrada, pp. 145-160, Virginia M. Fields y Dorie Reents-Budet (eds). México: Consejo Nacional para la Cultura y las Artes, Instituto Nacional de Antropología e Historia

Sherer, Andrew K. y Stephen Houston

2018 "Blood, Fire, Death. Convenants and Crises among the Classic Maya", Smoke, Flames, and the Human Body in Mesoamerican Ritual Practice, pp. 109-150, Vera Tiesler y Andrew K. Scherer (eds.). Washington, D.C.: Dumbarton Oaks Research Library and Collection.

Sheseña, Alejandro

2005 "Ritos de fuego nuevo en cuevas mayas", Bolom. Revista del Centro de Investigaciones Frans Blom, 2: 91-125.

2007 "Los textos jeroglíficos mayas de la cueva de Joljá, Chiapas", Mesoweb, 1-25, $<$ www.mesoweb.com/es/artículos/jolja/Jolja.pdf> [consultado 23 de abril de 2017].

2014 "El papel de las cuevas en las guerras de los antiguos mayas", Itinerarios, 19: 53-74.

2015 Joyaj ti 'ajawlel. La ascensión al poder entre los mayas clásicos. Tuxtla Gutiérrez: Universidad de Ciencias y Artes de Chiapas, Afinita Editorial.

Somohano, Ana y Antonio Jaramillo

2015 "Registro epigráfico de reentradas a tumbas mayas durante el periodo Clásico", XXIX Simposio de Investigaciones Arqueológicas en Guatemala, pp. 727-739. Guatemala: Museo Nacional de Arqueología y Etnología. 
Stone, Andrea y Mark Zender

2011 Reading Maya Art. A Hieroglyphic Guide to Ancient Maya Painting and Sculpture. Nueva York: Thames and Hudson.

Stuart, David

1998 “The Fire Enters His House'. Architecture and Ritual in Classic Maya Texts”, Function and Meaning in Classic Architecture, pp. 373-425, Stephen D. Houston (ed.). Washington D.C.: Dumbarton Oaks.

2010 Comentarios sobre las inscripciones del Templo XIX de Palenque. San Francisco: The Pre-Columbian Art Resarch Institute, <http://www.mesoweb.com/es/publicaciones/Stuart/TXIX.pdf> [http://www.mesoweb.com/es/publicaciones/ Stuart/TXIX.pdf>. Consultado el 18 de junio de 2016]

Tate, Carolyn E.

1992 Yaxchilán: The Design of a Maya Ceremonial City. Austin: University of Texas Press.

Taube, Karl

1988 “A Study of Classic Maya Scaffold Sacrifice”, Maya Iconography, pp. 330-351, Elizabeth P. Benson y Gillet G. Griffin (eds.). Princeton: Princeton University Press.

1992 The Major Gods of Ancient Yucatan. Washington D.C.: Dumbarton Oaks (Studies in Pre-Columbian Art and Archaeology, 32).

1998 "The Jade Hearth: Centrality, Rulership, and the Classic Maya Temple", Function and Meaning in Classic Architecture, pp. 427-478, Stephen D. Houston (ed.). Washington D.C.: Dumbarton Oaks.

2004 "Structure 10L-16 and Its Early Classic Antecedents: Fire and the Evocation and Resurrection of K'inich Yax K'uk' Mo'”, Understanding Early Classic Copan, pp. 265-295, Ellen E. Bell, Marcello A. Canuto y Robert Sharer (eds.). Philadelphia: University of Pennsylvania, Museum of Archaeology and Anthropology.

Tiesler, Vera, Oswaldo Chinchilla, Julio Chi Keb, Saúl Chay y Oswaldo Gómez

2013 "Fuego y sacrificio durante el Clásico Temprano: los restos humanos del Entierro PP7TT-01, Tikal”, XXVI Simposio de Investigaciones Arqueológicas en Guatemala, 2012, pp. 445-456, Bárbara Arroyo y Luis Alberto Méndez (eds.). Guatemala: Ministerio de Cultura y Deportes, Instituto de Antropología e Historia y Asociación Tikal.

Tiesler, Vera y Andrew K. Scherer (eds.)

2018 Smoke, Flames, and the Human Body in Mesoamerican Ritual Practice. Washington D.C.: Dumbarton Oaks Research Library and Collection.

Vega Villalobos, María Elena

2009 La historia de Ceibal en la época Clásica, tesis de maestría en Estudios Mesoamericanos. México: Universidad Nacional Autónoma de México, Programa de Posgrados en Estudios Mesoamericanos, Facultad de Filosofía y Letras, Instituto de Investigaciones Filológicas. 
2017 El gobernante maya. Historia documental de cuatro señores del periodo Clásico. México: Universidad Nacional Autónoma de México, Instituto de Investigaciones Históricas, Fideicomiso Felipe Teixidor y Monserrat Alfau de Teixidor.

Vega Villalobos, María Elena, Moisés Aguirre y José Crasborn

2012 "Entre escultores, textos e imágenes: la Estela C de Quiriguá”, XXV Simposio de Investigaciones Arqueológicas en Guatemala, 2011, pp. 1050- 1060, B. Arroyo, L. Paiz, y H. Mejía (eds.). Guatemala: Ministerio de Cultura y Deportes, Instituto de Antropología e Historia y Asociación Tikal.

Velásquez García, Erik

2006 “Iconografía real de K’ahk Tiliw Chan Yo’aat: política y fundación del mundo en Quiriguá, Guatemala, La imagen política, XVI Congreso Internacional de Historia del Arte, pp. 113-146. México, Universidad Nacional Autónoma de México, Instituto de Investigaciones Estéticas.

2010 "Los dioses remeros mayas y sus posibles contrapartes nahuas, Acta Mesoamericana, 22: 115-131.

Voss, Alexander W.

2001 “Astronomía y matemáticas", Los mayas. Una civilización milenaria, pp. 131143, Nikolai Grube (ed). Colonia: Kónemann.

Martha Ilia Nájera Coronado. Mexicana. Realizó sus estudios de licenciatura, maestría y doctorado en Historia en la Universidad Nacional Autónoma de México. Es investigadora del Centro de Estudios Mayas del Instituto de Investigaciones Filológicas de la misma universidad desde 1980 y docente del Posgrado de Estudios Mesoamericanos. Sus líneas de investigación se centran en la historia de la religión maya, con especial interés en el ritual y los mitos prehispánicos y coloniales desde una perspectiva multidisciplinaria. Su actual proyecto de investigación se titula "La simbólica del fuego en la cultura maya". Entre sus últimas publicaciones se encuentran Dioses y seres del viento entre los antiguos mayas, "¿Tenían los mayas un dios del viento?" y "El mono y el cacao: la búsqueda de un mito a través de los relieves del Grupo de la Serie Inicial de Chichén Itzá".

matina@unam.mx 